\title{
The Limits of Gaining Rights while Remaining Marginalized: The Deferred Action for Childhood Arrivals (DACA) Program and the Psychological Wellbeing of Latina/o Undocumented Youth
}

\author{
Caitlin Patler, University of California-Davis ${ }^{1}$ \\ Erin Hamilton, University of California-Davis \\ Robin Savinar, University of California-Davis
** This article has been accepted for publication in Social Forces, published by Oxford University Press. **

\begin{abstract}
Policies that expand the rights of marginalized groups provide an additional level of structural integration, but these changes do not always come with broad social acceptance or recognition. What happens when a legally marginalized group attains increased rights but not full political or social inclusion? In particular, what are the mental health implications of these transitions for impacted groups? We bring together theories of liminal legality and stress process to offer a framework for understanding how expansions in the legal rights of a highly politicized and vulnerable social group can be initially beneficial, but can attenuate due to renewed or new stress events, chronic stressors, and anticipatory stressors. We use the case of Latina/o immigrant youth who transitioned from undocumented legal status to temporarily protected status under the Deferred Action for Childhood Arrivals (DACA) program. Analyses of representative California statewide survey data from 2007-2018, combined with surveys and in-depth interviews with DACA recipients, suggest that without full social and structural inclusion, legal transitions that expand rights will produce short-term psychological benefits that do not hold up over time.
\end{abstract}

\section{KEY WORDS}

Liminal legality, stress process, undocumented immigrants, Deferred Action for Childhood Arrivals (DACA)

\footnotetext{
${ }^{1}$ Please direct all correspondence to Caitlin Patler: patler@ucdavis.edu

This work was supported by the National Science Foundation (Award \#\#1822787); American Sociological Association Spivack Community Action Research Award; National Academy of Education/Spencer Foundation; Sociological Initiatives Foundation; Hellman Foundation; University of California Center for New Racial Studies; University of California Institute for Mexico and the United States; UCLA Institute of American Cultures and the Chicano Studies Research Center; UCLA Institute for Research on Labor and Employment; UC Davis Academic Senate Faculty Research Grant; UC Davis Institute for Social Sciences; and UC Davis Center for Regional Change. We thank the staff at the UCLA Center for Health Policy Research Data Access Center for their generous assistance with the analysis of the California Health Interview Survey, and Ninez Ponce for her support of the project. We thank current and former members of Dream Team Los Angeles and the UC Davis DACA Research Team for their contributions to the DACA Longitudinal Study.
} 


\section{INTRODUCTION}

The legal expansion of rights to marginalized groups can enable structural integration into mainstream societal institutions. However, programs that expand the rights of marginalized groups are not always accompanied by broad social acceptance, and often involve social or political backlash. What happens when a marginalized group attains increased legal rights but continues to face social and/or political marginalization? In particular, what are the mental health implications of these transitions for impacted groups? We bring together insights from liminal legality theory and stress process theory to understand how and why rights-granting programs may initially improve mental health. We underscore how and why those improvements may be short-lived in the context of continued marginalization: Even with new rights, marginalized groups can experience new or renewed stress events, chronic stressors, and anticipatory stressors due to their marginalized status. Without permanent protections gained through full inclusion, legal transitions will result in short-term benefits to psychological wellbeing that do not hold up over time.

We advance our argument using the case of Latina/o undocumented immigrant youth who received temporary protected status under the Deferred Action for Childhood Arrivals (DACA) program. Announced by the Obama Administration in June 2012, DACA granted eligible undocumented youth temporary relief from deportation, access to work authorization, and access to other benefits, renewable every two years. ${ }^{1}$ As of September 2018, over 908,000 of the estimated 1.3 million young people eligible for DACA had participated in the program (Migration Policy Institute 2017, USCIS 2018).

While DACA granted recipients some fundamental rights - most importantly, the ability to work lawfully and to avoid deportation for unlawful presence, DACA recipients do not have 
access to permanent legal status nor a guarantee that DACA will remain in place. The DACA program has been highly contested in the national political climate. Throughout the U.S. presidential campaign season in 2015 and 2016, then-candidate Donald Trump stated that he would end DACA if elected. In September 2017, he made good on that promise by announcing plans to rescind the program. Although in June 2020 the Supreme Court denied the Trump Administration's efforts to terminate the program on procedural grounds, the future of DACA remains uncertain. This or future administrations could still end the program if it follows procedure - and the President has already threatened to do so. The legal status provided under DACA is therefore best understood as "liminal" - that is, temporary, contingent, and limited (Cebulko 2014, Menjívar 2006, Roth 2018).

We use two unique sources of data to understand the impact of the legal transitions introduced by DACA on the mental health of undocumented immigrant youth. First, we estimate the average short- and longer-term impacts of DACA on distress among Latina/o immigrants in the 2007-2018 waves of the California Health Interview Survey (CHIS). Our analyses reveal that DACA's impacts were closely linked to the political context. We observe a reduction in distress among the DACA-eligible in the immediate post-DACA period, from 2012-2015. However, DACA-eligible immigrants returned to pre-DACA levels of distress by mid-2015-a time period that corresponds to heightened anti-immigrant rhetoric during the U.S. presidential campaignand remained at pre-DACA stress levels thereafter.

To understand why and how the experiences of DACA recipients changed over time, we draw from the DACA Longitudinal Study (DLS), an original survey and in-depth interview study of Latina/o DACA recipients and undocumented non-recipients in California. Our analyses of the DLS reveal that DACA helped recipients overcome some of the structural disadvantages 
associated with undocumented immigration status, thereby initially reducing distress. However, improvements to mental health were not sustained as the national policy climate became increasingly hostile toward immigrants, underscoring DACA's liminal nature and emphasizing the marginality of DACA recipients.

These findings have immediate relevance to current policy debates about the futures of millions of undocumented and other immigrants in the United States. In 2019, the Supreme Court heard challenges to the DACA program, and Congress continued to consider policy changes to address the needs of DACA recipients. As of this writing, the program remains in effect for current recipients, but its future is in limbo. Other groups of immigrants-particularly those who transition from undocumented to other non-permanent visa categories, such as Temporary Protected Status (TPS) — also languish in uncertainty about the future of their status; our study's results are informative to understanding their health as well. Beyond immigrants, understanding the relationship between legal transitions and stress can inform research and policy on other marginalized groups who experience increases in rights while remaining socially marginalized, such as LGBTQ individuals after gay marriage legislation, or formerly incarcerated people in the wake of correctional reform programs. Understanding the role of policy in influencing health is critical to understanding inequality in the United States, given that mental health is socially determined and linked to both mobility and mortality.

\section{THEORETICAL FRAMEWORK}

We bring together theories of liminal legality and stress process to understand how an increase in rights among a legally and socially marginalized group may initially be protective for mental health, but can produce new or renewed stress events, chronic stressors, and anticipatory 
stressors, especially when there is social and/or political backlash that threatens newly gained rights.

Cecilia Menjívar's (2006) concept of liminal legality describes the "gray area between [documented and undocumented] legal categories, how this ‘in-between' status or liminal legality shapes different spheres of life" (Menjívar 2006:1000). Research on liminal legality has generally focused on recipients of TPS, which provides deportation relief and work authorization to immigrants fleeing crises in their home countries, but is subject to regular review and the potential for revocation. In her work on Salvadoran TPS holders, Menjívar has shown that longterm liminal legality threatens and undermines family life, work, school, social networks, and community supports - the very forces that promote immigrant integration and mental health (Menjívar 2006, Menjívar 2008, Menjívar and Abrego 2012).

Drawing on anthropological concepts of ambiguous and transitional periods, Menjívar (2006:1007) argues that "transitory stages are empowering and are positive moments in social transformation," but when they are extended indefinitely, liminality "loses its empowering potential." In that sense, liminal legality theory predicts that the transition from more to less legally vulnerable (i.e. from undocumented to "DACAmented") will be initially empowering but have diminishing benefits over time. While liminal legality theory has been immensely helpful for understanding the experiences of individuals in temporary legal status categories for long periods of time (Menjívar 2006, Menjívar and Abrego 2012), including undocumented youth prior to DACA (Nakano Glenn 2011), as well as those who transition out of liminal legality and into permanent legal status (Menjívar and Lakhani 2016), it has not been used to evaluate the initial transition out of undocumented status and into a liminally legal status. 
We bring liminal legality theory into conversation with stress process theory to explain why and how a structural situation that may initially reduce distress - in this case, becoming DACAmented after being undocumented — can become a chronic stressor that is linked to a series of anticipatory stresses, leading to an attenuation of the mental health benefits over time. Stress process theory describes stressors as "external circumstances that challenge or obstruct", and stress as the "internal dysfunctions that result from these circumstances" (Pearlin and Bierman 2013:326-7). Legally liminal statuses—such as undocumented status—impose structural challenges that obstruct mobility (e.g. discrimination, inability to work in the formal labor market, etc.) and can lead to long-term, chronic, and/or enduring stress. These stressors constitute excess stress that is linked to undocumented immigrants' stigmatized minority status, as predicted by minority stress process theory (Meyer 2003, Vega and Rumbaut 1991).

Legally vulnerable groups can also experience stigma, fear of informal or formal rejection or expulsion, and the loss of ontological security — the ability to count on the stability of the future (Vaquera, Aranda and Sousa-Rodriguez 2017). Consistent with the predictions of identity control theory (Thoits 1991), legally vulnerable young adults' mental health may also be influenced by discordance between their perceptions of self as individuals deserving of rights and their stigmatized political identities (Abrego 2011; see also Gee et al. 2016). These dissonant identity scenarios can become stress events that undermine psychological wellbeing. Studies conducted prior to DACA found that undocumented adolescents were more likely to exhibit clinical depression and anxiety, compared to their documented peers (Potochnick and Perreira 2010).

There are several mechanisms through which DACA may reduce stress, at least initially. For one, DACA removes at least two chronic stressors from young immigrants' lives: the daily 
threat of discovery and deportation and the inability to work legally. Alternatively, some chronic stressors may persist, new stress events may occur, and new anticipatory stressors may emerge, especially if the group remains socially or politically marginalized. Given DACA's temporary nature, recipients may continue to lack ontological security. New stress events, such as discriminatory public sentiment or threats to rights, may exacerbate these feelings.

Indeed, the acute political focus on DACA in the years following its announcement, and the overall uncertainty of the program's future, ${ }^{2}$ likely underscore DACA's liminality, bringing to the forefront anticipatory stress related to the potential loss of DACA status that may undermine any positive psycho-emotional effects of the program. Anticipatory stress is an understudied aspect of the stress process: "Unlike negative events and strains that have a current and active presence in the lives of people, anticipated stressors do not exist as realities but are viewed as having the potential to become so" (Pearlin and Bierman 2013:328). Anticipatory stress can be generated by observing hardship or victimization of other people within one's social network. For undocumented immigrants, this could include witnessing anti-immigrant actions such as raids, deportation, or discrimination within one's family or community (Valdivia 2018). This may be compounded for individuals with DACA who initially expected their new (albeit temporary) status to launch them into a period of stability and rights, but come to find that their status does not permanently or fully protect them. They may thus experience a new series of stress-inducing dissonant identity scenarios (Thoits 1991) in which their visions of themselves as individuals deserving of rights_-indeed, as individuals with some newfound rights_ — run up against the way others perceive them (Gee et al. 2016).

Anticipatory stress can also be generated at the structural or societal level. Pearlin and Bierman (2013) use the example of changes in the economy due to a recession: As "relatives, 
friends, neighbors, or coworkers" hear about financial hardships, or as these struggles become "daily subjects of media reports," then they become a source of anxiety and apprehension (Pearlin and Bierman 2013:328). For DACA recipients, anti-immigrant actions at the federal level likely act as anticipatory stressors even while the program is still in place - e.g. travel bans, the imprisonment of immigrant parents and young children, challenges to programs that would have extended DACA and created a complementary program for undocumented parents of U.S. citizens and LPRs (DAPA), ${ }^{3}$ and perhaps most importantly, the announcement of plans to eliminate DACA.

Importantly, these chronic and anticipatory stressors are rooted precisely in the experience of having been granted some rights, though not full inclusion. Menjívar and Lakhani (2016) describe the legal process of applying for citizenship as "transformative:" immigrants' views of themselves are permanently changed as they prepare application materials and make a legal case for formal political incorporation. As we will show, DACA recipients also begin a process of transformation when they receive their DACA status and are no longer living as undocumented immigrants. They expect their lives to improve both materially and symbolically. However, a climate of political and social uncertainty can disrupt this process, amplifying liminality instead of inclusion, creating anticipatory stress, and mitigating previous improvements to wellbeing.

In sum, liminal legality theory predicts that an initial transition to a liminal legal status may be empowering — though this premise has not been tested—but long-term liminality will be deleterious. Stress process theory articulates the mechanisms linking expansions in rights to psychological wellbeing among marginalized groups. Taken together, these theories generate a framework that explains why transitions into liminal legality (i.e. from fewer to greater rights) 
can produce short-term benefits that can evaporate when rights are threatened or when the limitations of those rights are tested.

\section{Undocumented Youth, DACA, and Legal Transitions}

The DACA program came about after more than a decade of advocacy for a path to citizenship for undocumented immigrants who came to the United States as children.

Undocumented youth organized national networks and engaged in targeted lobbying, advocacy, and civil disobedience (Nicholls 2013, Patler 2018a). When announcing DACA on June 15, 2012, President Obama emphasized that DACA was an opportunity to align the way that young undocumented immigrants feel and are perceived by many — as Americans — with their legal status.

A number of studies have examined the short-term impacts of DACA for eligible immigrants. These studies find overwhelmingly positive effects of DACA in the two-to-three years following its passage, including increased high school completion (Hamilton, Patler and Savinar 2020, Kuka, Shenhav and Shih 2020) and likelihood of employment (Amuedo-Dorantes and Antman 2017, Gonzales, Terriquez and Ruszczyk 2014, Kuka, Shenhav and Shih 2020, Pope 2016), decreased rates of poverty (Amuedo-Dorantes and Antman 2016), lower teen birth rates (Kuka, Shenhav and Shih 2019), stronger feelings of inclusion and belonging (Abrego 2018), and improvements to health and mental health for both DACA recipients and their children (Hainmueller et al. 2017, Patler and Pirtle 2018, Patler et al. 2019, Venkataramani et al. 2017).

Yet other research finds less optimistic effects. $=$ Hsin \& Ortega (2018) find decreased four-year college enrollment in the post-DACA period in New York (see also Pope 2016). It is possible that DACAmented individuals may prioritize their short-term options (to work) rather 
than long-term futures (Hamilton, Patler and Savinar 2020). This is consistent with qualitative work by Roth (2018), which finds that while DACA improved recipients' opportunities relative to their previous position as undocumented immigrants, they did not feel permanently protected.

The uncertainty of liminal legality was likely magnified during the U.S. presidential campaign in 2015-16 whrn then-candidate Trump overtly threatened DACA and immigrants' rights more broadly. ${ }^{4}$ In August 2015, when asked what he would do about DACA, Trump stated, "they have to go" [be deported]..$^{5}$ The November 2016 election was another turning point, not just for DACA recipients but arguably for all noncitizens and those who share households and communities with DACA recipients. Within weeks of his inauguration, Trump issued executive orders to further criminalize immigration violations, target all undocumented immigrants for deportation, and severely limit opportunities for asylum. Then, in September 2017, the Trump administration announced that it would phase out DACA. While the Supreme Court denied the administration's attempt to rescind the program in June 2020, it did so on procedural grounds only, leaving open the possibility a rescinding in the future. ${ }^{6}$

Despite findings from early studies of DACA suggesting that the program led to improvements in wellbeing, given the current contested reality of the DACA program, it is unclear how DACA recipients will fare in the long term. Population-based survey research from California suggests that threats to the DACA program were linked to declines in self-rated health among DACA-eligible immigrants as well as their children (Patler et al. 2019). By bringing together liminal legality and stress process theories, and relying on multiple and mixedmethodological data sources, we identify mechanisms that help explain why these improvements will not endure and may be reversed when rights are threatened. 


\section{METHODS}

We rely on two sources of data from California, which is home to nearly a third of DACA applicants (USCIS 2018). We estimate population-level impacts of DACA on psychological wellbeing using the 2007-2018 waves of the California Health Interview Survey (CHIS). Then, to examine the mechanisms influencing these impacts, we draw from the DACA Longitudinal Study (DLS), an original, longitudinal survey and in-depth interview study of DACA recipients and undocumented non-recipients in California. We describe these data sources and our analytical strategies below.

\section{California Health Interview Survey (CHIS)}

\section{$\underline{\text { Data }}$}

The CHIS is a population-based telephone survey of California's residential, noninstitutionalized population collected by UCLA's Center for Health Policy Research in collaboration with the California Department of Public Health and the Department of Health Care Services. This repeated (annual or biannual) cross-sectional survey includes a detailed set of legal status questions that allow for a closer identification of the DACA-eligible population and relevant control groups than in most other population-level data sets (more on this below). We use adult and teen surveys from the 2007-2018 CHIS waves. ${ }^{7}$ We focus on Latina/o-origin ${ }^{8}$ individuals who make up the vast majority (94 percent) of DACA applicants (USCIS 2018).

\section{Analytical Strategy}

We utilize a difference-in-differences (DID) approach designed to compare the impacts of a "treatment" on a "treatment group," compared to a "control group," before and after the 
treatment is introduced. In our case, the treatment is DACA, the treatment group is Latina/o DACA-eligible immigrants, and the control group is Latina/o documented immigrants who share a similar profile in terms of the DACA eligibility criteria. In the Appendix, we compare the DACA-eligible to two other control groups: undocumented-ineligible and U.S. born Latina/os. ${ }^{9}$ In an experimental setting, the researcher would randomly allocate DACA status to individual study participants. Of course, in the real world that is impossible. We therefore rely on DACA as a "natural experiment" given the arbitrary — or exogenous — timing of the treatment. One key test of the appropriateness of the DID design is to verify that the treatment and control groups followed parallel trends prior to the treatment; if that is the case, then we can assume that DACA explains any difference that emerges between groups following the treatment. We assessed parallel pre-trends by estimating the interaction between each pre-DACA survey year across the comparison groups, as well as testing the differences between the groups (first differences) and across DACA-period (second differences). Statistically significant differences would indicate a differential pre-trend. Figure 1 shows average differences in the outcome variables (K6 score and moderate-to-severe K6 scores) between the DACA-eligible and the documented control group. Appendix Table 1 shows coefficients and tests of first and second differences for all pre-trend models; see Appendix Figure 1 for comparisons with the undocumented-ineligible and U.S.-born control groups. These results indicate parallel preDACA trends in each of our outcomes of interest, demonstrating the appropriateness of the DID design.

-Figure 1 about here-

We hypothesized that DACA's impacts will not be uniform over time, but will respond to the fluctuating stability of the program. Figure 1 suggests this hypothesis may be true. To capture 
the politically-relevant cutpoints that are linked to changes in trends, we compare the pre-DACA period to three post-treatment periods that correspond to stages of relative stability or threat to the program. The pre-DACA period includes CHIS respondents interviewed between January 1 , 2007 (the earliest CHIS wave-year that matches DACA eligibility criteria) and June 14, 2012 (the day before DACA was announced). We consider June 15, 2012 (DACA's announcement) through June 16, 2015 (the day before the announcement of Donald Trump's presidential bid) as the first post-DACA period (the "Stability" period). This period is characterized by relative optimism about, and few explicit threats to, DACA. The second post-period, June 17, 2015 November 8, 2016 (Trump's announcement through the date of the presidential election), is characterized by highly publicized anti-immigrant rhetoric and threats to the DACA program, but not explicit action against it (the "Threats" period). The third post-period begins after the election (November 9, 2016) and extends through January 2019 (the final date for which CHIS 2018 wave data are available). This period is characterized by regular and hostile federal actions toward immigrants - e.g. travel bans, proposals to severely limit asylum and family-based visa petitions, increased targeting of undocumented immigrants for deportation, and most importantly, the announcement of plans to eliminate DACA (the "Election \& Beyond" period).

\section{Equation 1}

$$
\begin{aligned}
& Y=\beta_{0}+\beta_{1} \text { Treat }+\beta_{2} \text { post } 1+\beta_{3} \text { post } 2+\beta_{4} \text { post } 3+\beta_{5}(\text { Treat } \cdot \text { post } 1)+ \\
& \beta_{6}(\text { Treat } \cdot \text { post } 2)+\beta_{7}(\text { Treat } \cdot \text { post } 3)+\beta_{8}(\text { covariates })+\varepsilon
\end{aligned}
$$

Equation 1 shows a dynamic treatment DID regression equation that corresponds to these politically-relevant cutpoints. The interaction terms between the treatment group (DACA- 
eligible) and each of the post-period dummies $\left(\beta_{5}\right.$ through $\left.\beta_{7}\right)$ are interpreted as the (intent-totreat) effect of DACA during each period. If, as hypothesized, the beneficial impacts of DACA diminish in the context of the presidential campaign and election, the DID interaction for the first post-period will be negative and significant, corresponding to decreases in distress, while it would be less negative or positive (and not statistically significant) for the second and third postperiod, as distress scores revert to the pre-DACA mean.

We use negative binomial and logistic regressions to model the count and binary outcomes (described further below). Because interaction terms should not be interpreted in nonlinear models without further testing (Mize 2019), we examine the average predicted K6 count (for the negative binomial model) and the average predicted probability of moderate-to-severe distress (for the logit model). We also calculate Average Marginal Effects (AMEs) for the models (first differences) and use post-estimation tests to compare the statistical significance of the pre-post differences between the DACA-eligible and each of the control groups (second differences).

Measures

Identifying Legal Status

A key advantage of the CHIS over other data sets such as the American Community Survey or the Current Population Survey is that the CHIS asks a more detailed series of questions to foreign-born respondents to determine their legal status. ${ }^{10} \mathrm{We}$ compare one treatment group (the DACA-eligible) to documented immigrants. Respondents who are naturalized citizens or lawful permanent residents ("LPRs") are documented and those who are neither citizens nor LPRs are defined as (likely) undocumented. While the CHIS does not allow 
for an exact identification of the DACA-eligible, our estimates will be more precise than those of past studies, which grouped LPRs, who comprise 40 percent of noncitizens under age 35, with the DACA-eligible (Acosta, Larsen and Grieco 2014). Our estimates are likely to be more accurate, given that only 7 percent of Latina/o non-citizen, non-LPRs are estimated to have legal documents, such as a temporary student or work visa (Bustamante et al. 2012). As a sensitivity test, we also limited our analyses to respondents of Mexican-origin, whose population includes even smaller shares of temporary visa holders than Latina/o-origin immigrant groups (U.S. Department of State 2017), and find similar results to the main analysis.

\section{Dependent and Control Variables}

Our analysis relies on the Kessler 6-question psychological distress scale (K6). The K6 scale was designed as part of the mental health component of the U.S. National Health Interview Survey and is widely used across the social, behavioral, and medical sciences. The K6 score is a count that can range from zero to 24 points. ${ }^{11}$

We include two dependent variables. First, we use the respondent's K6 score during the 30 days prior to the survey interview date. To model this outcome, we use negative binomial regression, which accounts for both the count structure of the variable as well as for overdispersion. We then model a dichotomous variable indicating whether or not the respondent experienced moderate-to-severe psychological distress $(\mathrm{K} 6>=5)$ during the past 30 days (Prochaska et al. 2012). This threshold identifies individuals with levels of distress that are clinically relevant and warrant mental health intervention. Both the count and logit models control for respondent's age, self-reported gender (male or female), and household income as a percentage of the Federal Poverty Level. 


\section{The DACA Longitudinal Study (DLS)}

\section{$\underline{\text { Data }}$}

The DLS is an original, longitudinal study of immigrant youth in California. The DLS includes telephone surveys and in-depth interviews and was designed to assess both longitudinal changes as a result of DACA program participation as well as the mechanisms that explain these changes. Respondents were drawn from a pool of individuals who attended at least one DACA informational session in Los Angeles County between 2012-2014. ${ }^{12}$ The original study was fielded in 2014-2015 and included 502 telephone surveys (Latina/o n=493) followed by 62 indepth interviews with a subset of survey participants in 2015-2016. The Wave 2 survey was conducted in 2018-2019 and included 300 of the original Latina/o respondents. In preparation for Wave 2, we also conducted a series of preliminary interviews in 2018. In each survey, respondents are asked approximately 50 questions about their education and employment trajectories, community involvement, and health and wellbeing. ${ }^{13}$

The DLS in-depth interviews were designed to capture whether, how, and why DACA changed the lives of participants. Interviewees were selected from the telephone survey sample to include male- and female-identifying individuals of diverse ages as well as individuals with/without DACA, with/without postsecondary education, involved/not involved in community organizations, and who are of Mexican vs. other origin. ${ }^{14}$ Table 1 shows the demographic characteristics and DACA status of DLS samples.

-Table 1 about here-

The DLS has several advantages over existing in-depth research on DACA recipients. First, it is one of the only studies we are aware of that follows the same group of individuals 
longitudinally, which allow us to observe the contingency and dynamism of the program's effects as the policy context changes. The DLS data capture a five-year period that roughly spans the Stability, Threats, and Election \& Beyond periods.

The DLS is also unique in that it does not primarily sample activists or university students, as is the recruitment method in other studies that directly sample DACA recipients. Indeed, only 27 percent of DLS respondents were affiliated with immigrants' rights organizations ${ }^{15}$ and only 13 percent had a college degree (for work drawn predominantly from samples of activists or college students, see Gonzales, Terriquez and Ruszczyk 2014, Hsin and Ortega 2018, Teranishi, Suárez-Orozco and Suárez-Orozco 2015, Wong et al. 2017).

\section{Analytical Strategy}

Open-ended survey data and in-depth interview data were recorded and transcribed and then analyzed using Dedoose software. We followed the flexible coding strategy outlined by Deterding and Waters (2018). We began by creating an open coding tree based on published work on immigrant legal status and wellbeing (e.g. Gee et al. 2016, Patler and Pirtle 2018, Vaquera, Aranda and Sousa-Rodriguez 2017, Venkataramani et al. 2017). As we proceeded through the transcripts, we added codes and themes inductively. To ensure inter-coder reliability, each interview was coded by at least two research team members and discussed at a weekly team meeting. We also used Dedoose's intercoder reliability check to systematize the codes across team members. After the first two rounds of coding, we completed a third round of coding to organize the codes into themes related to re-emerging and new stress events, chronic stressors, and anticipatory stress experiences. These codes provide context for, and illustration of, the mechanisms behind our legal transitions framework. We also examined descriptive statistics 
from closed-ended DLS questions on psychological wellbeing (described in Table 1); these quantitative data were cleaned, coded, and analyzed using Stata.

\section{FINDINGS}

\section{Descriptive Statistics}

Table 2 shows the weighted characteristics of the CHIS sample by legal status and treatment period. We focus our comparisons to the documented control group, but include information for the undocumented-ineligible and U.S.-born control groups in the Appendix. During the pre-DACA period, average K6 scores in the past 30 days hovered around four across the groups, and the DACA-eligible immigrants' scores were not statistically different from the documented. However, during the Stability Period, DACA-eligible respondents had significantly better mental health reports than the control group: K6 scores of 2.71 for the DACA-eligible, compared to 4.45 for the documented. The likelihood of moderate-to-severe distress was also significantly lower for the DACA-eligible during the Stability period: only 19 percent of DACAeligible had moderate-to-severe level of distress (down from 38 percent in the pre-period), compared to 35 percent of the documented control group in both the pre-DACA period and the Stability period. However, during the Threats and Election \& Beyond periods (June 17, 2015November 8, 2016 and November 9, 2016-January 31, 2019, respectively), DACA-eligible immigrants' overall K6 and moderate-to-severe scores were higher and no longer statistically different from the control group.

Table 2 also shows respondents' background characteristics. The groups have comparable gender distributions, but DACA-eligible people are younger and have lower household incomes, on average, than the control group. 


\section{Regression Results}

We now turn to our dynamic treatment effects DID models comparing the change in K6 scores from the pre-period to the post-periods for Latina/o DACA-eligible, compared to documented immigrants (Equation 2). Figure 2 shows the predicted K6 score based on the negative binomial model in Panel 1 of Appendix Table 2. Predicted K6 scores declined by 30 percent from the pre-period to the first post-period (from 3.94 to 2.74) for DACA-eligible youth. The AME and contrast results in Appendix Table 2 confirm that these declines were statistically significant, compared to documented immigrants. However, Figure 2 also show that improvements to psychological wellbeing for DACA-eligible immigrants during the Stability period were not sustained during the second and third post-periods (the Threats and Electionand-Beyond periods).

-Figure 2 about here-

-Figure 3 about here-

The results for our DID logistic regression analysis of moderate-to-severe distress scores $(K 6>=5)$ follow a similar trajectory (Appendix Table 2). Figure 3 shows that the predicted probability of moderate-to-severe psychological distress declined by nearly half from the preperiod to the first post-period (from 37 percent to 20 percent) for the DACA-eligible, compared to the documented. However, as with overall K6 scores, the probability of moderate-to-severe distress increased during the Threat and Election-and-Beyond periods, to 26 and 36 percent, respectively. These changes in predicted probability no longer represent a statistically significant 
difference from documented immigrants whose predicted probability of moderate-to-severe distress hovers between 31 and 36 percent across all four periods. Results comparing DACAeligible to undocumented-ineligible and U.S.-born groups (Appendix Table 2 and Appendix Figure 2) largely mirror the comparison with documented immigrants.

\section{Explaining initial decreases in distress}

Why might we see initial improvements to psychological wellbeing among the DACAeligible? To answer this question, we draw from responses to the first wave of the DLS, gathered from DACA recipients in late 2014 and early 2015, when most had DACA status for 12 to 18 months. These responses offer insight into the mechanisms behind the changes we observed in psychological wellbeing in the population-level survey data. Overall, DACA recipients were extremely optimistic about the program during this period. As Table 1 shows, while 74 and 75 percent of DLS respondents reported increased distress and negative emotions, respectively, in retrospective accounts of the 12-month period before they had DACA, those percentages dropped to 16 and 18 percent, respectively, in Wave 1 (2014). When DLS respondents were asked an open-ended question about what had changed most for them since receiving DACA, 97 percent of respondents mentioned that things had generally improved, citing a combination of instrumental factors and reduced fear/increased freedom, which we describe below.

At its most basic level, DACA operates as an instrumental aid to socioeconomic incorporation by providing work authorization and access to identification, which can relieve economic burdens (a chronic stressor) faced by many undocumented youth. As one respondent described in 2014, "I have a better job, I am more stable, and not afraid to drive around. I have an ID now and I am more capable to do what I want. I feel better emotionally, physically, and 
psychologically." Another said, "[receiving DACA] was really emotional. I felt relieved... I was gonna get out of high school... It gave me the whole world! I'm gonna find a job. And then I was gonna be able to have the chance to get an education" (emphasis added).

The DACA program also initially removed a second chronic stressor from recipients' lives: the daily threat of discovery and deportation. Indeed, deferred action is a discretionary determination not to deport someone who is otherwise eligible for removal from the United States. As long as a DACA recipient maintains the program's eligibility criteria and the program itself remains in place, the government is unlikely to deport them. Many DACA recipients felt an initial wave of relief upon receiving their new status. One recipient described it like this: " $D A C A$ gave me the security of knowing that you can actually be outside without worrying that you'll get deported."

Likewise, DACA may also affect youths' identities and understandings of their belonging in the United States. DACA recipients felt less excluded, more optimistic, and more integrated into American sociocultural and political life. They perceived less discrimination. One respondent told us, "[DACA] brings a lot of benefits: better job and more work and you can actually apply for healthcare. In a sense, it brings you into the community." Another said, "[DACA brings me] Peace. [I can] breathe better. Hope. And knowing I exist. I feel like I belong and other people know I exist." As these quotes demonstrate, in the short-term after DACA's passage, many recipients were relieved of chronic and anticipatory stressors related to deportation threat and other structural barriers linked to their formerly-undocumented status, and they felt greater consistency between their identities and their legal status.

\section{Explaining subsequent increases in distress}


While DACA was linked to significant improvements to mental health in the immediate post-DACA period, distress scores in the CHIS data reverted to pre-DACA levels during the presidential election period starting around June 2015. The DLS survey data support this conclusion: distress and negative emotions due to legal status rose nearly to pre-DACA levels by 2018 (62 and 59 percent, respectively; see Table 1). To describe mechanisms for this finding, we turn to DLS data collected during the second and third post-periods, in 2015-2016 and 2018-19, respectively. The interviews reveal that DACA recipients experienced new or renewed stress events, chronic stressors, and anticipatory stressors throughout the presidential campaign and election. DLS respondents cited stressors that were linked to legal status in ways that were both familiar (i.e. renewed stressors they had experienced as undocumented immigrants) and new (i.e. stressors related to the limitations and uncertainties of DACA and the lack of full social membership).

First, by mid-2015, some respondents began to realize that the program was not a permanent solution and could be revoked in a changing political context. This led some to feel their goals were still unattainable, or to feel worried about making long-term decisions. Consider the following quote:

I'm deciding if I want to go back to school to obtain a Master's degree and weighing the pros and cons. If I take out a personal loan for $\$ 40,000$ and at the end of the day I am on an ongoing DACA renewing basis, what happens if the next president comes along and changes things or what if... what if $D A C A$ renewal gets harder and I invested in my education all this money and I'm not able to get a job, and pay back all of that money that I took out. 
As in this quote, anticipatory stress about the future of the program began to weigh on some respondents.

Second, in 2015 and 2016, some respondents described how even with DACA, they were surprised and disappointed to experience stress events and chronic stress related to barriers and stigma they had faced as undocumented immigrants. One DACA recipient described her experiences applying for jobs: "I feel that still ... even with DACA...there's still discrimination out there." Other chronic and anticipatory stressors were renewed for DACA recipients. For instance, most DACA recipients continued to worry about family members who remained undocumented: "Well first I thought by getting DACA [my family would be safer] ... but now even after [DACA], I can see that parents are getting deported."

Such feelings intensified as the presidential election got underway. Respondents described the distress they felt when seeing then-candidate Trump's remarks on the campaign trail in 2015 and 2016 (see Notes 2 and 4). Many respondents described these speeches as stress events that triggered a new way of thinking about the DACA program - and their own identities — as uncertain and precarious. One respondent said:

[I feel] stress, as in, not knowing my future...stressing who the next president is... Are they racist? Are they gonna take this DACA off? 'Cause Obama's the one who passed it, right?... so that creates stress and anxiety for sure. Another respondent expressed similar anticipatory stress regarding the uncertainty of the election: "It's real, it is there, it can happen. If the leadership of this country changes and decided to do something different about us, then we're screwed or detained...that concern has been there for me." Stress events related to the precariousness of the program became chronic, anticipatory stressors. 
2015 included another stressful period for DACA recipients: federal litigation against efforts to expand deferred action status to a greater subset of the undocumented population. DLS respondents worried about the DAPA program and the lack of protections for their undocumented parents: "I want my family to be legal... 'cause...DAPA was stopped.” For DLS respondents, the fact that DAPA and Extended DACA were so vulnerable underscored DACA's own liminality.

By 2018, the tone of DLS responses was even more sober. Respondents described this period as "terrifying" and "shocking." They described panic attacks; uncontrollable bouts of crying; trouble sleeping; difficulty concentrating on work or schoolwork; and feelings of betrayal, distrust, and skepticism in the government. Their process - and expectations - of permanent transformation and/or acceptance due to DACA appear to have been thwarted. One DACA recipient described it like this: "[Before the election period] I would tell everyone I had DACA. In class, at work, to my teachers. I was very proud to finally feel more included, more normal " (emphasis added). However, after the election, this respondent no longer felt protected by DACA: "I stopped telling people I have DACA because I don't feel protected by it anymore." Another said, "DACA has been wonderful in the benefits that it has provided, allowing me to work, study, and drive with less fear. I had hoped it would provide a transition to a more permanent solution [for my legal status], but that doesn't seem to be the case, especially with the current president and government. The fear of DACA being taken away is constantly on my mind." 


\section{DISCUSSION}

What happens when a legally and socially marginalized group attains increased rights without full inclusion? We bring together stress process theory and liminal legality theory to explain how transitions into liminal statuses can produce new or renewed stress events, chronic stressors, and anticipatory stressors when groups remain marginalized and/or threatened. Using the case of the DACA program, we showed that DACA led to immediate, short-term improvements in eligible immigrants' mental health, as it initially reduced or relieved chronic and anticipatory stressors such as deportation threat and exclusion from the formal labor market. However, DACA's mental health benefits dissipated as the national political climate underscored the liminal nature of the program, thereby bringing about new and old chronic stressors, stress events, and anticipatory stressors.

Our research makes several theoretical and empirical contributions. In bringing together stress process and liminal legality theories, we build upon and bring into conversation two bodies of research that have developed in relative isolation from one another. Liminal legality theory (Menjívar 2006) predicts that an expansion of rights will be empowering in the short-term but disabling in the long-term. We offer the first test of this theoretical prediction and find support for it. Stress process theory explains why this happens by defining specific mechanisms that relate social experiences to (di)stress. In addition, while the literature on stress process and minority stress process is robust, we broaden this literature to further identify the role that legal status - and specifically transitions from legal exclusion to liminal inclusion-can play in fomenting or enhancing stress events, chronic stressors, and anticipatory stressors. Understanding legal status, itself produced by the law, as a determinant of mental health is critical for understanding individual and community health more broadly, and for identifying 
policy solutions to combat health inequalities. Stress process theory provides a framework to clarify how legal status "gets under the skin" to affect mental health outcomes.

We also build on liminal legality theory by underscoring the new and renewed stress events and chronic and anticipatory stressors that drive the dissipation of DACA's positive impacts on mental health. We argue that these stressors are rooted precisely in the experience of having been granted a limited expansion of rights. Menjívar and Lakhani (2016) describe the legal process of applying for citizenship—i.e., full political inclusion—as transformative for immigrants. We have shown that DACA recipients also begin a process of transformation when they receive DACA status. They expect their lives to improve both materially and symbolically. However, in a hostile political climate, DACA recipients' lack of social inclusion run up against their expectations of membership and belonging, leading to new and re-emerging chronic and anticipatory stressors and dissonant identity experiences, that ultimately undermine the program's benefits.

Our study also makes several methodological contributions. First, the combination of methods - survey data analysis and in-depth interview analysis—-is essential to understanding DACA's impacts on mental health by presenting overall population-based trends as well as indepth evidence of mechanisms. Second, our datasets extend research on DACA in several ways. Most importantly, the CHIS allows for a more precise definition of immigrant legal status than is available in most population-based data. Specifically, it allows us to identify non-LPRs among noncitizens, therefore more accurately identifying the DACA-eligible treatment group. We also examine a longer post-period (through early 2019) than most existing studies. The DLS is also unique, most importantly in its longitudinal design and direct identification of DACA status, which allows us to triangulate and explain patterns in the statewide data by following the same 
group of respondents over time. All of these features allow us to show the dynamic and changing impacts of the program.

These theoretical and empirical contributions notwithstanding, our study has limitations that may be improved upon in future research. First, our focus on California, while home to nearly a third of DACA applicants, may not represent the experiences of DACA recipients elsewhere. California is known to have a pro-immigrant statewide policy context (Rodríguez, Young and Wallace 2015), though it contains more local variation in immigration policy than many other states (García 2019). Future studies should more closely examine the potential heterogeneity of DACA's impacts at the county or city level. Similarly, given the racialization of legal status (Asad and Clair 2018, Cho 2017, Patler 2014, Patler 2018b), studies that examine the potentially spillover effects of DACA onto immigrant groups who did not qualify for the program (e.g. Patler et al. 2019), as well as outcomes across ethnic groups would provide a fuller accounting of DACA's impacts. Likewise, examining the experiences of DACA recipients across age cohorts and age-at-receipt of DACA would also expand our understanding of the program's impacts, but investigating heterogeneity in DACA's impacts necessitates larger data sets.

We have theorized how and why rights-granting programs or rights attainment may fall short of producing long-term positive impacts on mental health or other aspects of wellbeing, especially when these transitions are impermanent or do not correspond to increased social inclusion or reduced discrimination for the groups in question. The case of DACA supports this theorization, but our framework is also relevant to other groups of immigrants who transition from fewer to greater rights, as long as those rights remain temporary or contingent (Plascencia 2012). We expect our results would be especially strong in political climates that underscore the 
temporary nature of liminally legal categories, threaten rights, and emphasize immigrants' marginality. Future research can assess the applicability of our findings to other immigrant groups.

Our framework is also useful beyond immigrant communities for research concerned with other socially marginalized groups experiencing legal transitions. Indeed, our results are consistent with research on LGBT communities that documents improvements to health when rights are expanded (e.g. following the legalization of gay marriage) (Hatzenbuehler et al. 2012), but also shows that improvements may not persist when a group remains stigmatized (Thomeer et al. 2018). Our framework may also inform research on the experiences of former prisoners who experience initial optimism about the prospects of life after incarceration, followed by disillusionment with the vast structural barriers and workplace discrimination they face (Sugie 2018).

\section{CONCLUSION}

Our findings have immediate relevance to policy debates about the uncertain futures of millions of immigrants and their loved ones in the United States. The June 2020 Supreme Court decision has kept DACA safe for now, yet there is widespread concern about the future of the program. Indeed, President Trump has already threatened to rescind the program by following legal procedure. ${ }^{16}$ As DACA continues to face debate on the national political stage, the mental health and wellbeing of more than one million young people hang in limbo. For these immigrants who grew up in the United States, DACA was the first formal gesture of political inclusion from the federal government in the country they consider home. Symbolically, DACA offered a sense of hope, possibility, and recognition; materially, it provided the opportunity to improve 
employment and educational attainment. However, DACA recipients' wellbeing is routinely undermined by an anti-immigrant political climate that directly threatens the program's future. These threats foment substantial anxiety, fear, and distress, exacerbate DACA recipients' legal precarity, and challenge their feelings of belonging in America. Our research suggests that without opportunities for permanent inclusion, the long-term mental health of DACA recipients—and other liminally legal immigrants—will remain in jeopardy. 
Table 1. DACA Longitudinal Study Latina/o Respondent Characteristics (n=300)

\begin{tabular}{|c|c|c|c|}
\hline & $\frac{\text { Pre-DACA }}{\text { (Retrospective) }}$ & $\frac{\text { Wave } 1}{(2014)}$ & $\frac{\text { Wave } 2}{(2018)}$ \\
\hline Has DACA Status & 0.00 & 0.92 & 0.85 \\
\hline Male & - & 0.40 & - \\
\hline Age in years (range) & - & $24(18-33)$ & $28(22-37)$ \\
\hline Low-income & 0.94 & 0.46 & 0.27 \\
\hline $\begin{array}{l}\text { Increased stress, nervousness, or anxiety due to } \\
\text { legal status }\end{array}$ & 0.74 & 0.16 & 0.62 \\
\hline Increased negative emotions due to legal status & 0.75 & 0.18 & 0.60 \\
\hline
\end{tabular}

Notes: Gender asked only at Wave 1. Low-income during pre-DACA period based on eligibility for free or reduced lunch during K-12; wave 1 and 2 based on trouble paying utility bills in the past year. To capture psychological wellbeing, respondents were asked: "In the past year, because of your legal status, did you experience: 1) increased stress, nervousness or anxiety; 2) increased anger; 3) increased fearfulness; 4) increased sadness; 5) increased embarrassment or shame." We created a binary variable for negative emotions to reflect whether the respondent had experienced any of \#2-5 above $(1=$ Yes). These questions are not meant to be clinical measures; instead, their purpose was to measure self-reported levels of psychological wellbeing that immigrant youth perceived to be directly impacted by their legal status. The questions were developed and revised in consultation with undocumented youth organizations and tested in a series of focus groups with undocumented individuals. For the sake of longitudinal comparison, results for Wave 1 include only individuals who participated in both waves of the survey; results are substantively similar for the full Wave 1 sample. 


\section{Table 2. Weighted Characteristics of CHIS Sample, by Legal Status and Time Period}

\begin{tabular}{|c|c|c|c|c|c|c|c|c|c|c|c|c|c|c|c|c|}
\hline \multirow[b]{3}{*}{$\begin{array}{l}\text { K6 Score, 0- } \\
24 \text { (mean) }\end{array}$} & \multicolumn{4}{|c|}{$\begin{array}{c}\text { Pre-DACA } \\
\text { (January 1, } 2007 \text { - June 15, 2012) }\end{array}$} & \multicolumn{4}{|c|}{$\begin{array}{c}\text { Stability } \\
\text { (June 16, 2012 - June 16, 2015) }\end{array}$} & \multicolumn{4}{|c|}{$\begin{array}{c}\text { Threats } \\
\text { (June 17, 2015 - November 8, 2016) }\end{array}$} & \multicolumn{4}{|c|}{$\begin{array}{c}\text { Election and Beyond } \\
\text { (November 9, } 2016 \text { - January 31, 2019) }\end{array}$} \\
\hline & $\begin{array}{l}\text { DACA- } \\
\text { elig. }\end{array}$ & $\begin{array}{l}\text { Docu- } \\
\text { mented }\end{array}$ & $\begin{array}{l}\text { Undoc.- } \\
\text { inelig. }\end{array}$ & $\begin{array}{l}\text { U.S.- } \\
\text { born }\end{array}$ & $\begin{array}{l}\text { DACA- } \\
\text { elig. }\end{array}$ & $\begin{array}{l}\text { Docu- } \\
\text { mented }\end{array}$ & $\begin{array}{l}\text { Undoc.- } \\
\text { inelig. }\end{array}$ & $\begin{array}{l}\text { U.S.- } \\
\text { born }\end{array}$ & $\begin{array}{l}\text { DACA- } \\
\text { elig. }\end{array}$ & $\begin{array}{c}\text { Docu- } \\
\text { mented }\end{array}$ & $\begin{array}{l}\text { Undoc.- } \\
\text { inelig. }\end{array}$ & $\begin{array}{l}\text { U.S.- } \\
\text { born }\end{array}$ & $\begin{array}{l}\text { DACA- } \\
\text { elig. }\end{array}$ & $\begin{array}{l}\text { Docu- } \\
\text { mented }\end{array}$ & $\begin{array}{l}\text { Undoc.- } \\
\text { inelig. }\end{array}$ & $\begin{array}{l}\text { U.S.- } \\
\text { born }\end{array}$ \\
\hline & 4.03 & 3.72 & 4.32 & 4.20 & 2.71 & $4.45^{*}$ & $4.77^{*}$ & $4.46^{*}$ & 3.43 & 3.66 & 2.95 & 4.35 & 4.36 & 4.41 & 3.31 & 4.98 \\
\hline $\begin{array}{l}\text { Moderate-to- } \\
\text { severe } \\
\text { distress, } \\
\text { K6>=5 } \\
\text { (proportion) }\end{array}$ & 0.38 & 0.35 & 0.40 & 0.31 & 0.19 & $0.35^{*}$ & $0.40 *$ & $0.42 *$ & 0.25 & 0.31 & 0.30 & $0.40^{*}$ & 0.35 & 0.35 & 0.27 & 0.46 \\
\hline $\begin{array}{l}\text { Age in years } \\
\text { (mean) }\end{array}$ & 17.53 & $21.43^{*}$ & $24.36^{*}$ & $19.15^{*}$ & 20.75 & $24.42 *$ & $25.30^{*}$ & $22.10^{*}$ & 23.19 & $26.00 *$ & $27.80^{*}$ & 22.87 & 22.38 & $26.96^{*}$ & $27.71^{*}$ & 23.40 \\
\hline $\begin{array}{l}\text { Male } \\
\text { (proportion) }\end{array}$ & 0.49 & 0.51 & 0.51 & 0.51 & 0.55 & 0.46 & 0.51 & 0.49 & 0.54 & 0.44 & 0.43 & 0.51 & 0.49 & 0.46 & 0.46 & 0.51 \\
\hline $\begin{array}{l}\text { Household } \\
\text { income (as } \\
\text { times } 100 \% \\
\text { of FPL) }\end{array}$ & 1.15 & $2.19 *$ & 1.16 & $2.81 *$ & 1.19 & $2.48^{*}$ & 1.52 & $2.66^{*}$ & 1.73 & $2.88^{*}$ & 1.40 & $3.00 *$ & 1.70 & $3.07 *$ & 2.37 & $3.61 *$ \\
\hline Observations & 404 & 722 & 249 & 4,769 & 108 & 281 & 78 & 1,977 & 88 & 274 & 171 & 2,093 & 83 & 312 & 122 & 2,566 \\
\hline
\end{tabular}

Notes: Source: 2007-2018 California Health Interview Survey. Sample is Latinas/os who meet the following DACA eligibility criteria: aged 15-30 in 2012, have a high school

diploma or GED, are currently enrolled in school, or served in the U.S. armed forces. The DACA-eligible and Documented satisfy the additional criterion of entering the U.S.

during or before 2007. * Significant difference from DACA-eligible ( $p<.05$, two-tailed test) 
Figure 1.

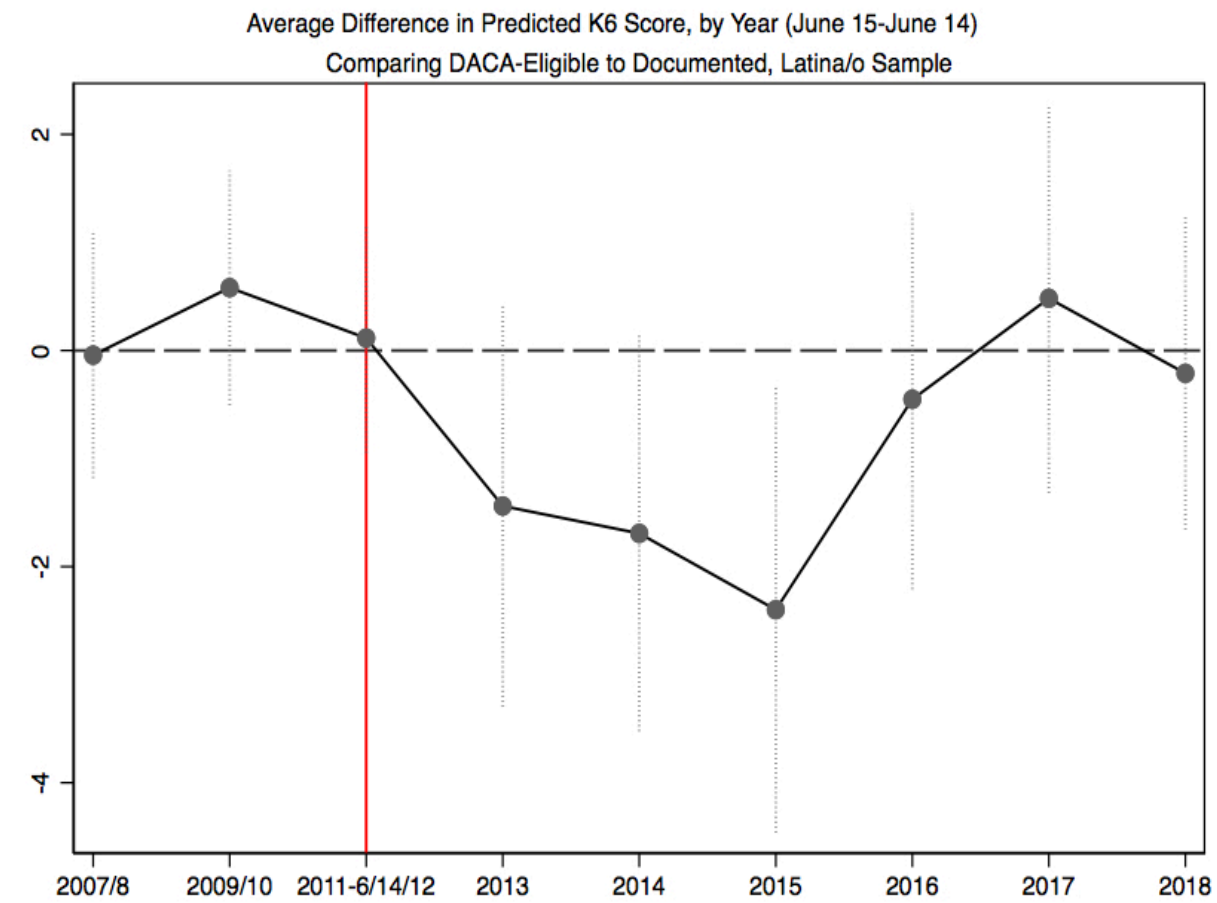

Average Difference in Predicted Probability of Moderate-to-Severe Distress (K6>=5), by Year (June 15-June 14) Comparing DACA-Eligible to Documented, Latina/o Sample

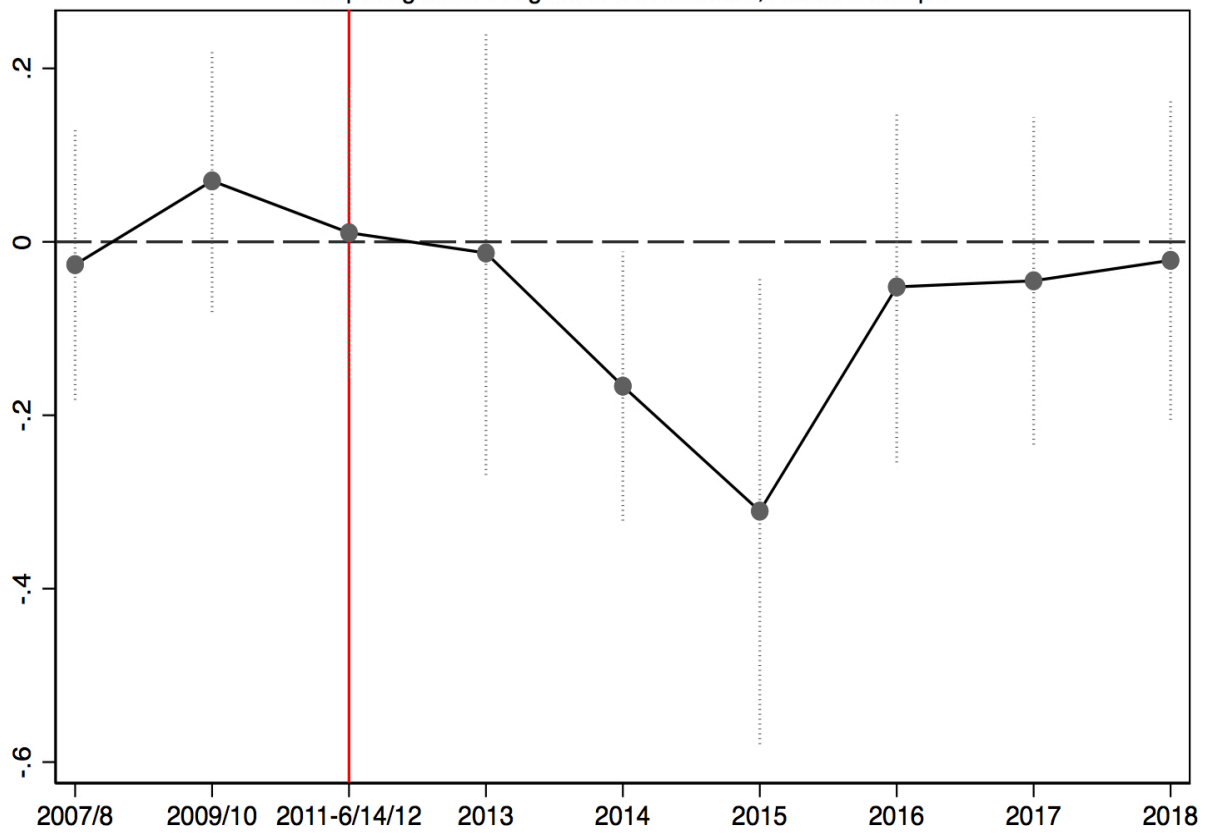

Notes: Source: 2007-2018 California Health Interview Survey. Sample is Latinas/os, ages 15-30 in 2012, who have a high school diploma or GED, are currently enrolled in school, or served in the U.S. armed forces. Models control for age in years, male, and household income (as times $100 \%$ of FPL). Solid vertical line represents DACA's announcement. Dotted vertical lines represent $95 \%$ confidence intervals.

Patler, Hamilton \& Savinar - 31 
Figure 2.

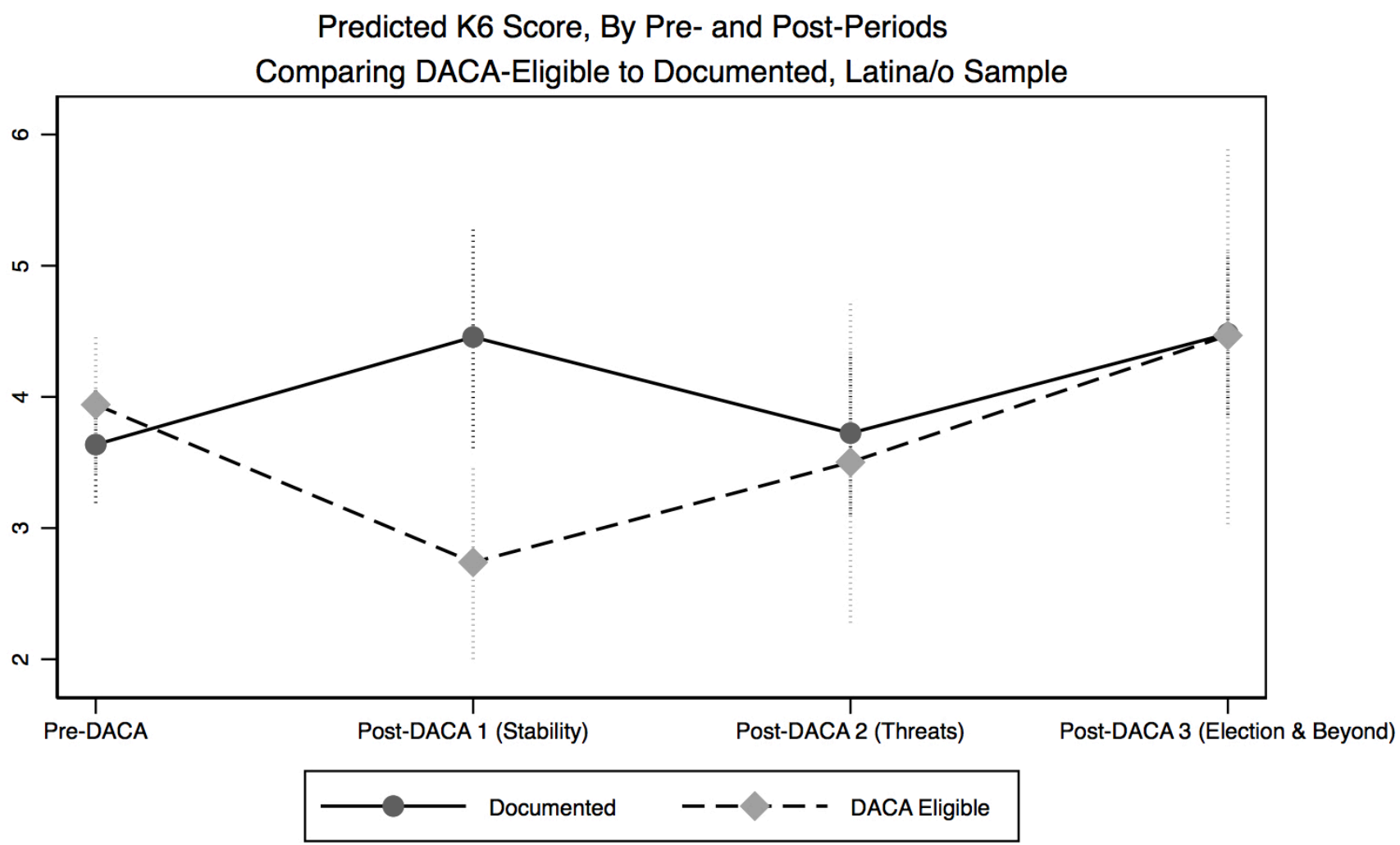

Notes: Source: 2007-2018 California Health Interview Survey. Sample is Latinas/os, ages 15-30 in 2012, who have a high school diploma or GED, are currently enrolled in school, or served in the U.S. armed forces. Models control for age in years, male, and household income (as times $100 \%$ of FPL). Predicted K6 scores are based on DID results shown in Appendix 2. Dotted vertical lines represent $95 \%$ confidence intervals.

Patler, Hamilton \& Savinar - 32 


\section{Figure 3.}

\section{Predicted Probability of Moderate-to-Severe Distress (K6>=5), By Pre- and Post-Periods Comparing DACA-Eligible to Documented, Latina/o Sample}

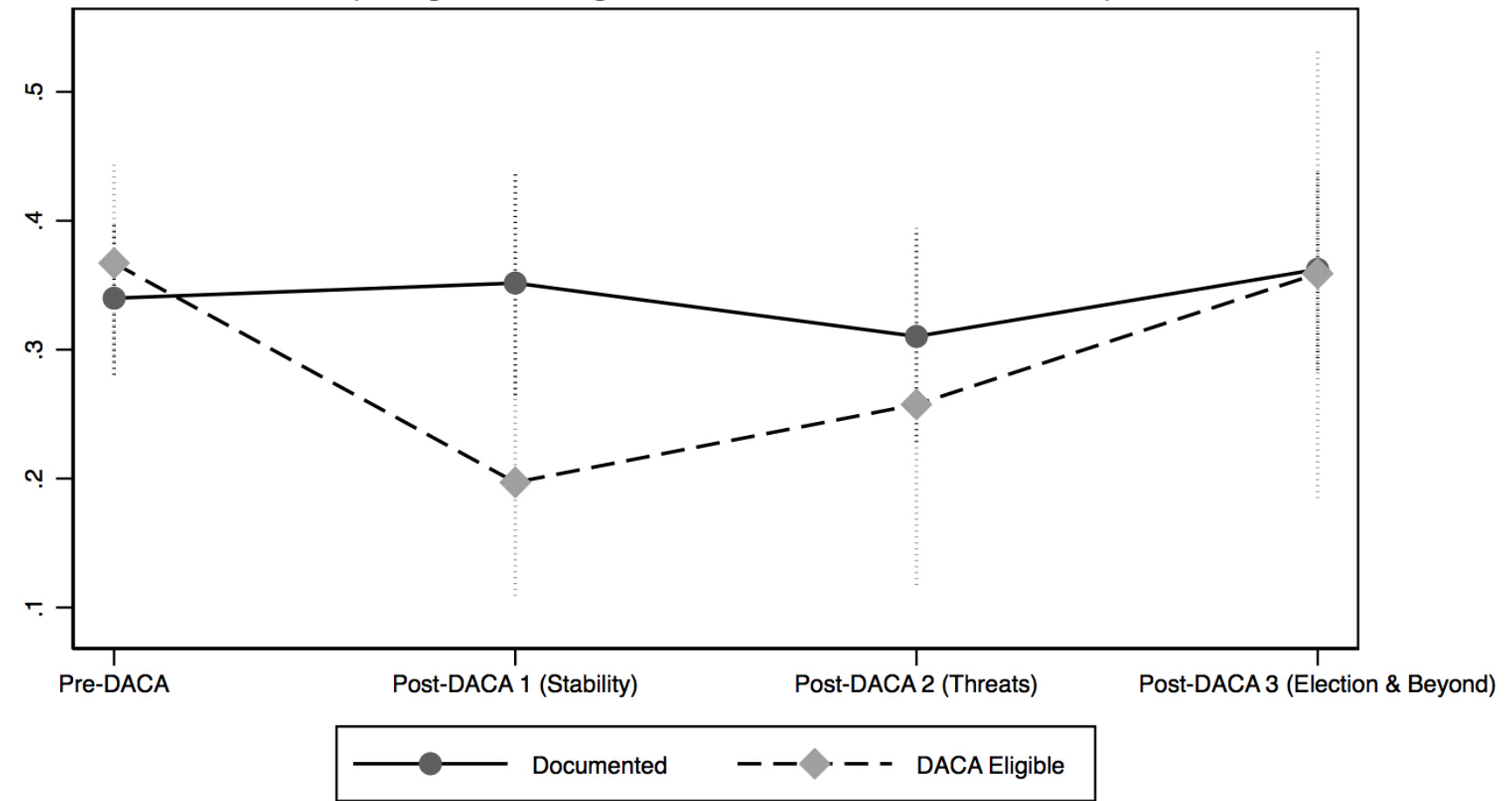

Notes: Source: 2007-2018 California Health Interview Survey. Sample is Latinas/os, ages 15-30 in 2012, who have a high school diploma or GED, are currently enrolled in school, or served in the U.S. armed forces. Models control for age in years, male, and household income (as times 100\% of FPL). Predicted K6 scores are based on DID results shown in Appendix 2. Dotted vertical lines represent 95\% confidence intervals. 


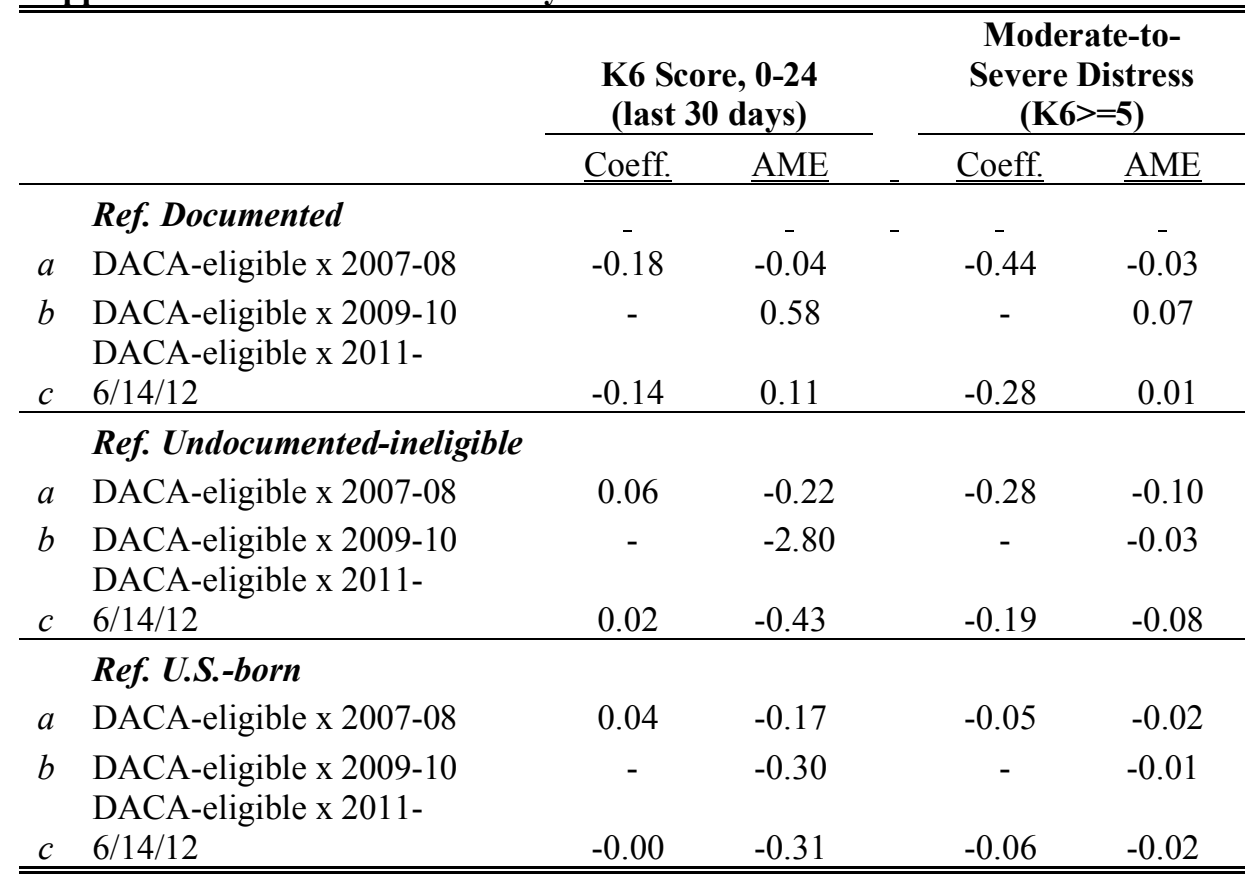

Notes: Source: 2007-2018 California Health Interview Survey. Sample is Latinas/os, ages 15-30 in 2012, who have a high school diploma or GED, are currently enrolled in school, or served in the U.S. armed forces. Reference year is 2009-10. Models control for age in years, male and household income (as times 100\% of FPL). None of the coefficients, average marginal effects (AME, or first differences), or mental health gaps across the pre-DACA periods (second differences) are statistically different from zero, confirming parallel pre-trends. 


\begin{tabular}{|c|c|c|c|c|c|c|c|c|c|}
\hline & & $\begin{array}{c}\text { K6 Score, } \\
\text { 0-24, last } 30 \\
\text { days } \\
\text { (Negative } \\
\text { Binomial } \\
\text { Regression) }\end{array}$ & SE & AME & Contrasts & $\begin{array}{c}\text { Moderate- } \\
\text { to-Severe } \\
\text { Distress } \\
\text { (K6 }>=5 \text { ) } \\
\text { (Logistic } \\
\text { Regression) }\end{array}$ & SE & AME & Contrasts \\
\hline & \multicolumn{9}{|l|}{$\begin{array}{l}\text { Ref. Documented } \\
\text { and pre-DACA }\end{array}$} \\
\hline & DACA-elig. & 0.06 & $(0.09)$ & - & - & 0.09 & $(0.21)$ & - & - \\
\hline & Post-DACA 1 (Stability) & $0.20+$ & $(0.12)$ & - & - & 0.05 & $(0.23)$ & - & - \\
\hline & $\begin{array}{l}\text { Post-DACA } 2 \text { (Threats) } \\
\text { Post-DACA } 3 \text { (Election \& }\end{array}$ & 0.02 & $(0.11)$ & - & - & -0.14 & $(0.24)$ & - & - \\
\hline & Beyond) & $0.21 *$ & $(0.10)$ & - & - & 0.10 & $(0.23)$ & - & - \\
\hline$a$ & DACA-elig. x Pre-DACA & - & - & 0.21 & $b$ & - & - & 0.02 & $b$ \\
\hline$b$ & DACA-elig. x Post 1 & $-0.57 * *$ & $(0.19)$ & $-1.80^{* *}$ & $a$ & $-0.92 *$ & $(0.40)$ & $-0.16^{*}$ & $a$ \\
\hline$c$ & DACA-elig. $x$ Post 2 & -0.14 & $(0.21)$ & -0.31 & & -0.38 & $(0.47)$ & -0.06 & \\
\hline \multirow[t]{7}{*}{$d$} & DACA-elig. x Post 3 & -0.08 & $(0.19)$ & -0.12 & & -0.13 & $(0.47)$ & -0.01 & \\
\hline & $\begin{array}{l}\text { Constant } \\
\text { Observations }\end{array}$ & $\begin{array}{c}1.52 * * * \\
2,272\end{array}$ & $(0.13)$ & - & - & $\begin{array}{l}-0.17 \\
2,272\end{array}$ & $(0.34)$ & - & - \\
\hline & \multicolumn{9}{|l|}{$\begin{array}{l}\text { Ref. Undoc.-inelig. } \\
\text { and pre-DACA }\end{array}$} \\
\hline & DACA-elig. & -0.11 & $(0.13)$ & - & - & -0.31 & $(0.31)$ & - & - \\
\hline & Post-DACA 1 & 0.11 & $(0.17)$ & - & - & 0.06 & $(0.41)$ & - & - \\
\hline & Post-DACA 2 & $-0.36^{*}$ & $(0.16)$ & - & - & -0.28 & $(0.42)$ & - & - \\
\hline & Post-DACA 3 & -0.23 & $(0.16)$ & - & - & -0.45 & $(0.38)$ & - & - \\
\hline$a$ & DACA-elig. x Pre-DACA & - & - & -0.46 & & - & - & -0.07 & \\
\hline$b$ & DACA-elig. x Post 1 & $-0.48^{*}$ & $(0.23)$ & $-2.18 * *$ & $c, d$ & $-0.91+$ & $(0.53)$ & $-0.24^{*}$ & $d$ \\
\hline$c$ & DACA-elig. $x$ Post 2 & 0.24 & $(0.25)$ & 0.40 & $b$ & -0.16 & $(0.57)$ & -0.10 & \\
\hline \multirow[t]{7}{*}{$d$} & DACA-elig. x Post 3 & 0.35 & $(0.22)$ & 0.92 & $b$ & 0.50 & $(0.56)$ & 0.04 & $b$ \\
\hline & $\begin{array}{l}\text { Constant } \\
\text { Observations }\end{array}$ & $\begin{array}{c}1.62^{* * *} \\
1,303 \\
\end{array}$ & $(0.25)$ & - & - & $\begin{array}{c}0.29 \\
1,303 \\
\end{array}$ & $(0.62)$ & - & - \\
\hline & \multicolumn{9}{|l|}{$\begin{array}{l}\text { Ref. U.S.-born } \\
\text { and pre-DACA }\end{array}$} \\
\hline & DACA-elig. & -0.06 & $(0.07)$ & - & - & -0.08 & $(0.17)$ & - & - \\
\hline & Post-DACA 1 & $0.07 *$ & $(0.03)$ & - & - & $0.23 * *$ & $(0.08)$ & - & - \\
\hline & Post-DACA 2 & 0.06 & $(0.04)$ & - & - & 0.14 & $(0.10)$ & - & - \\
\hline & Post-DACA 3 & $0.20^{* * *}$ & $(0.04)$ & - & - & $0.41 * * *$ & $(0.09)$ & - & - \\
\hline$a$ & DACA-elig. x Pre-DACA & - & - & $\begin{array}{c}-0.25 \\
-\end{array}$ & $b$ & - & - & $\begin{array}{c}-0.02 \\
-\end{array}$ & $b$ \\
\hline$b$ & DACA-elig. x Post 1 & $-0.45 * *$ & $(0.16)$ & $1.78 * * *$ & $a$ & $-1.09 * *$ & $(0.34)$ & $0.24 * * *$ & $a$ \\
\hline$c$ & DACA-elig. x Post 2 & -0.19 & $(0.19)$ & -0.97 & & -0.63 & $(0.41)$ & $-0.15^{*}$ & \\
\hline$d$ & DACA-elig. x Post 3 & -0.08 & $(0.18)$ & -0.67 & & -0.41 & $(0.43)$ & -0.12 & \\
\hline & Constant & $1.60^{* * *}$ & $(0.06)$ & - & - & 0.06 & $(0.14)$ & - & - \\
\hline & Observations & 12,082 & & & & 12,082 & & & \\
\hline
\end{tabular}


Notes: Source: 2007-2018 California Health Interview Survey. Pre-DACA=1/1/07-12/14/12; Post-DACA 1 =6/16/12-6/16/15 (Stability); Post-DACA 2 = 6/17/15-11/8/16 (Threats); Post-DACA $3=11 / 9 / 16-1 / 31 / 19$ (Election and beyond). Sample is Latinas/os, ages 15-30 in 2012, who have a high school diploma or GED, are currently enrolled in school, or served in the U.S. armed forces. Models control for age in years, male and household income (as times 100\% of FPL). *** $p<0.001, * * p<0.01, * p<0.05,+p<0.1$ The AME column reports the average marginal effect of DACA on mental health outcomes by legal status (first differences). The "contrasts" column reports which mental health gaps are significantly different (at $p<0.05$ ) across the pre-DACA, Post-DACA 1 (Stability), Post-DACA 2 (Threats), and Post-DACA 3 (Election-and-Beyond) periods. 
Appendix Figure 1.
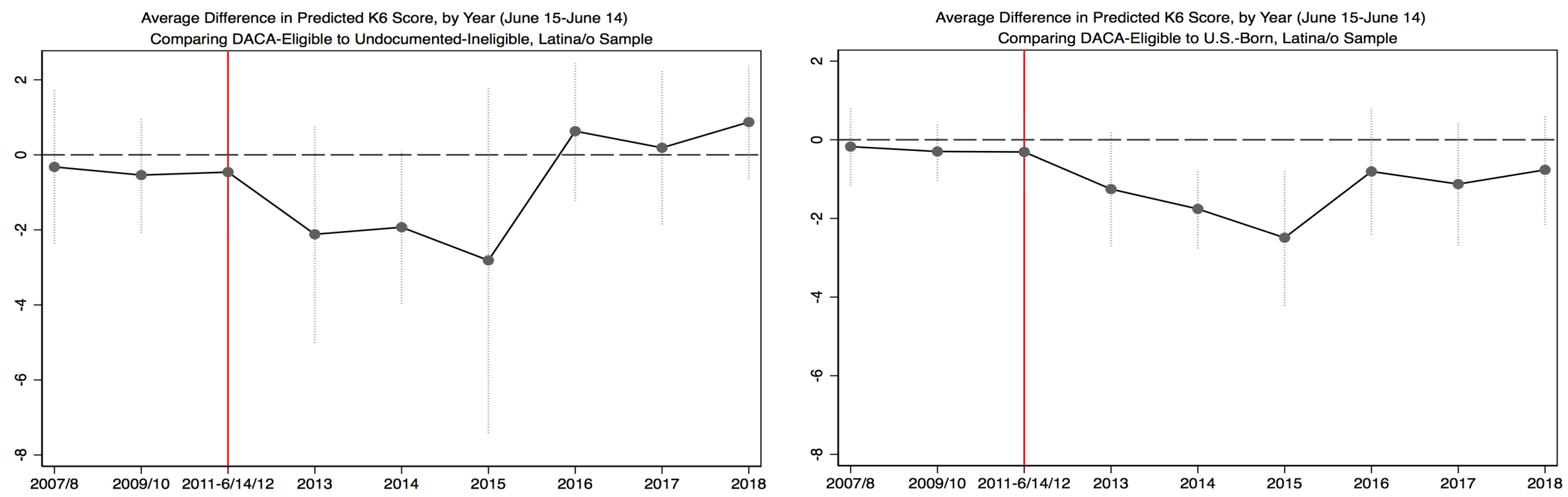

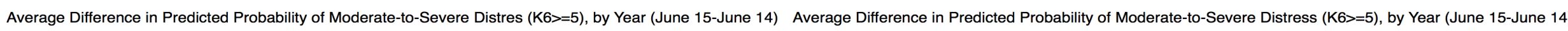
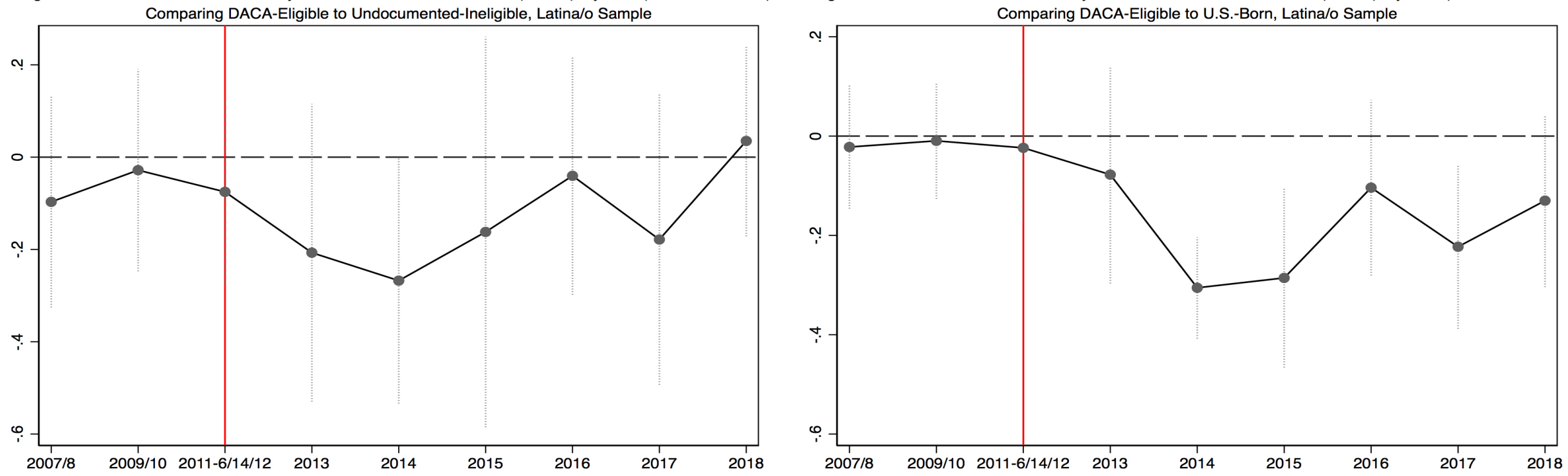

Notes: Source: 2007-2018 California Health Interview Survey. Sample is Latinas/os, ages 15-30 in 2012, who have a high school diploma or GED, are currently enrolled in school, or served in the U.S. armed forces. Models control for age in years, male and household income (as times 100\% of FPL). Solid vertical line represents DACA's announcement. Dotted vertical lines represent $95 \%$ confidence intervals.

Patler, 


\section{Appendix Figure 2.}

Predicted K6 Score, By Pre- and Post-Periods

Comparing DACA-Eligible to Undocumented-Ineligible, Latina/o Sample

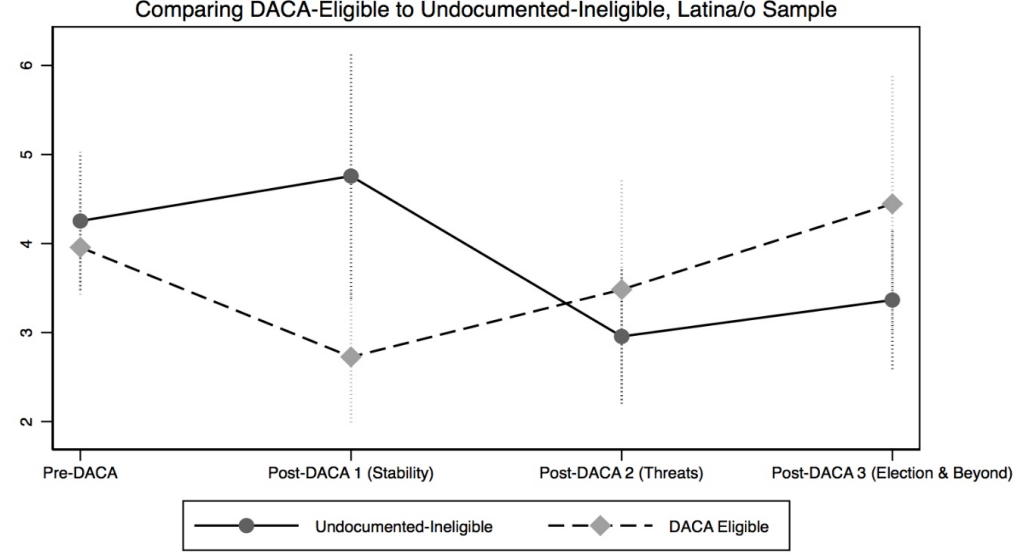

Predicted Probability of Moderate-to-Severe Distress (K6 $>=5$ ), By Pre- and Post-Periods Comparing DACA-Eligible to Undocumented-Ineligible, Latina/o Sample

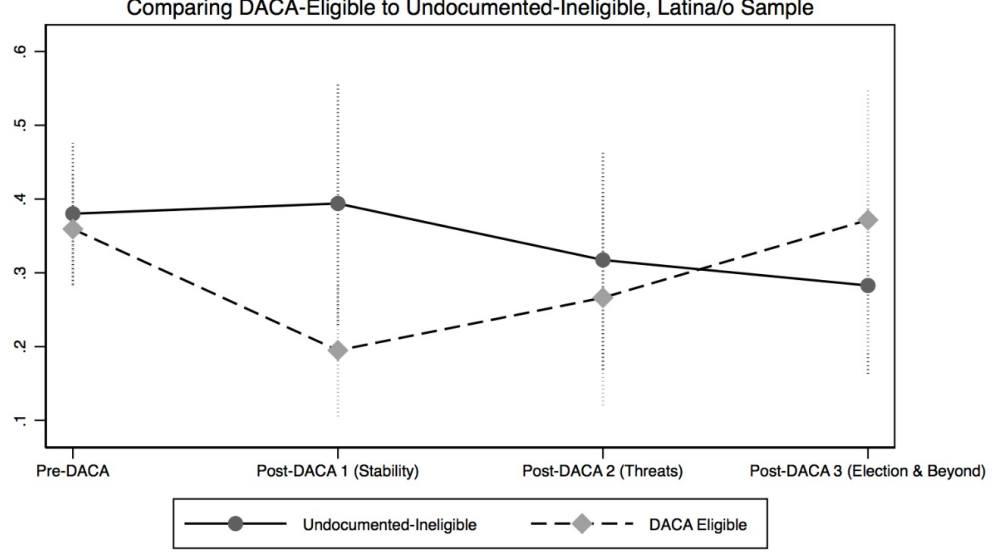

Predicted K6 Score, By Pre- and Post-Periods

Comparing DACA-Eligible to U.S.-Born, Latina/o Sample

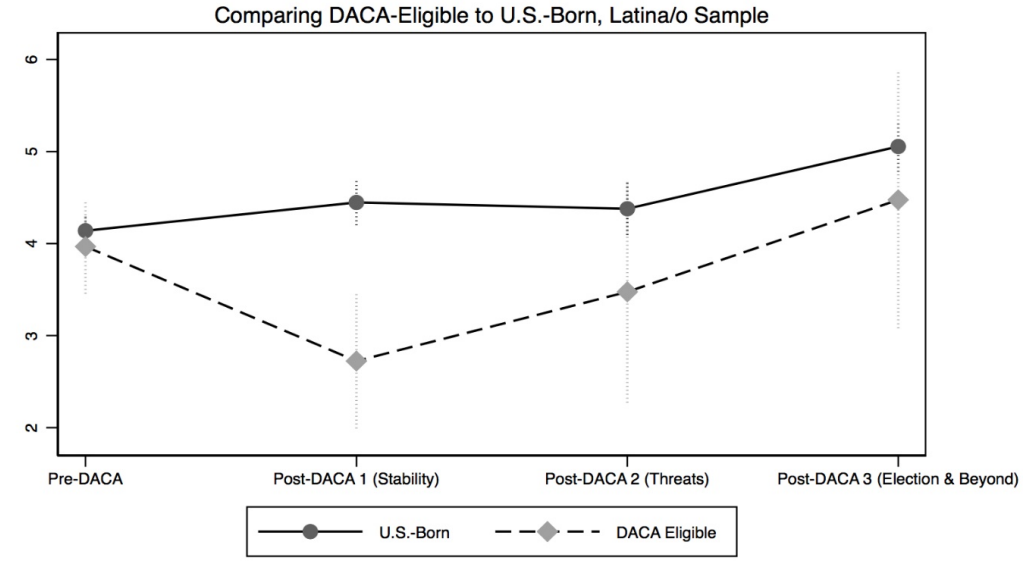

Predicted Probability of Moderate-to-Severe Distress $(K 6>=5$ ), By Pre- and Post-Periods Comparing DACA-Eligible to U.S.-Born, Latina/o Sample

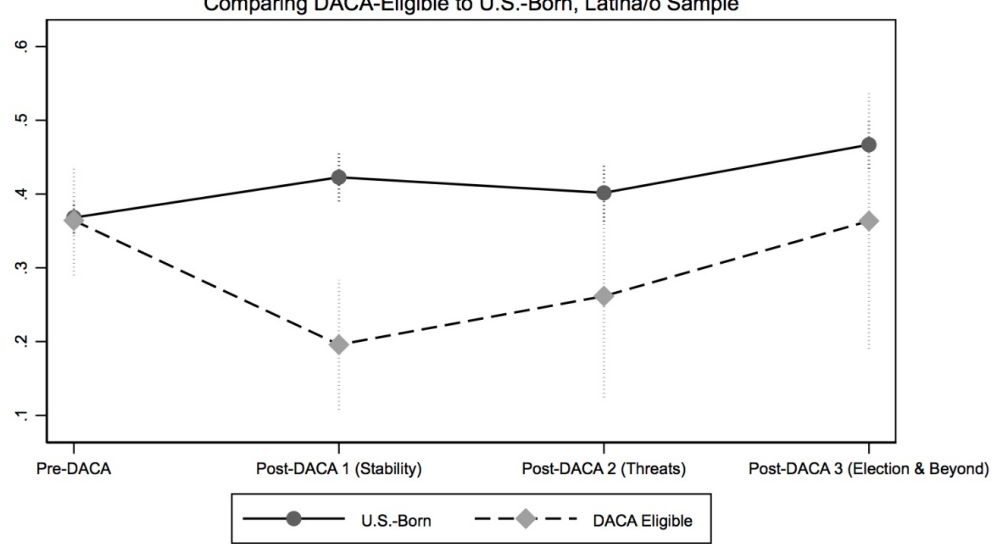

Notes: Source: 2007-2018 California Health Interview Survey. Sample is Latinas/os, ages 15-30 in 2012, who have a high school diploma or GED, are currently enrolled in school, or served in the U.S. armed forces. Models control for age in years, male, and household income (as times 100\% of FPL). Predicted K6 scores are based on DID results shown in Appendix Table 2. Dotted vertical lines represent 95\% confidence intervals. 


\section{REFERENCES}

Abrego, Leisy J. 2011. "Legal Consciousness of Undocumented Latinos: Fear and Stigma as Barriers to Claims-Making for First- and 1.5-Generation Immigrants." Law \& Society Review 45(2):337-69.

Abrego, Leisy J. 2018. "Renewed Optimism and Spatial Mobility: Legal Consciousness of Latino Deferred Action for Childhood Arrivals Recipients and Their Families in Los Angeles." Ethnicities 18(2):192-207. doi: 10.1177/1468796817752563.

Acosta, Yesenia D., Luke J. Larsen and Elizabeth M. Grieco. 2014. "Noncitizens under Age 35: 2010-2012." American Community Survey Briefs. Report Number: ACSBR/12-06.: U.S. Census Bureau.

Amuedo-Dorantes, Catalina and Francisca Antman. 2016. "Can Authorization Reduce Poverty among Undocumented Immigrants? Evidence from the Deferred Action for Childhood Arrivals Program." Economic Letters 147:1-4.

Amuedo-Dorantes, Catalina and Francisca Antman. 2017. "Schooling and Labor Market Effects of Temporary Authorization: Evidence from Daca." Journal of Population Economics 30(1):339-73.

Asad, Asad and Mathew Clair. 2018. "Racialized Legal Status as a Social Determinant of Health." Social Science \& Medicine 199(1):19-28.

Bustamante, Arturo V., Hai Fang, Jeremiah Garza, Olivia Carter-Pokras, Steven P. Wallace, John A. Rizzo and Alexander N. Ortega. 2012. "Variations in Healthcare Access and Utilization among Mexican Immigrants: The Role of Documentation Status." Journal of Immigrant and Minority Health 14(1):146-55.

Cebulko, Kara. 2014. "Documented, Undocumented, and Liminally Legal: Legal Status During the Transition to Adulthood for 1.5-Generation Brazilian Immigrants." The Sociological Quarterly 55(1):143-67.

Cho, Esther Yoona. 2017. "Revisiting Ethnic Niches: A Comparative Analysis of the Labor Market Experiences of Asian and Latino Undocumented Young Adults." RSF: The Russell Sage Foundation Journal of the Social Sciences 3(4):97-115.

Deterding, Nicole M. and Mary C. Waters. 2018. "Flexible Coding of in-Depth Interviews: A Twenty-First-Century Approach." Sociological Methods \& Research Online first:1-32.

García, Angela S. 2019. Legal Passing: Navigating Undocumented Life and Local Immigration Law: University of California Press.

Gee, Gilbert C., Brittany N. Morey, Katrina M. Walsemann, Annie Ro and David T. Takeuchi. 2016. "Citizenship as Privilege and Social Identity: Implications for Psychological Distress." American Behavioral Scientist 60(5):680-704.

Gonzales, Roberto G., Veronica Terriquez and Stephen P. Ruszczyk. 2014. "Becoming Dacamented: Assessing the Short-Term Benefits of Deferred Action for Childhood Arrivals (Daca)." American Behavioral Scientist 58(14):1852-72.

Hainmueller, Jens, Duncan Lawrence, Bernard Black Linna Martén, Lucila Figueroa, Michael Hotard, Tomás R. Jiménez, Fernando Mendoza, Maria I. Rodriguez, Jonas J. Swartz and David D. Laitin. 2017. "Protecting Unauthorized Immigrant Mothers Improves Their Children's Mental Health." Science 357(6355):1041-44. doi: 10.1126/science.aan5893.

Hamilton, Erin, Caitlin Patler and Robin Savinar. 2020. "Transition into Liminal Legality: Daca's Mixed Impacts on Education and Employment among Young Adult Immigrants in California." Social Problems Online first. 
Hatzenbuehler, Mark L., Conall O’Cleirigh, Chris Grasso, Kenneth Mayer, Steven Safren and Judith Bradford. 2012. "Effect of Same-Sex Marriage Laws on Health Care Use and Expenditures in Sexual Minority Men: A Quasi-Natural Experiment." American Journal of Public Health 102(2):285-91.

Hsin, Amy and Francesc Ortega. 2018. "The Effects of Deferred Action for Childhood Arrivals on the Educational Outcomes of Undocumented Students." Demography Online First. doi: 10.1007/s13524-018-0691-6.

Kuka, Elira, Na'ama Shenhav and Kevin Shih. 2019. "A Reason to Wait: The Effect of Legal Status on Teen Pregnancy." AEA Papers and Proceedings 109:213-17.

Kuka, Elira, Na'ama Shenhav and Kevin Shih. 2020. "Do Human Capital Decisions Respond to the Returns to Education? Evidence from Daca." American Economic Journal: Economic Policy 12(1):293-324. doi: https://doi.org/10.1257/pol.20180352.

Menjívar, Cecilia. 2006. "Liminal Legality: Salvadoran and Guatemalan Immigrants' Lives in the United States." American Journal of Sociology 111(4):999-1037.

Menjívar, Cecilia. 2008. "Educational Hopes, Documented Dreams: Guatemalan and Salvadoran Immigrants' Legality and Educational Prospects." The ANNALS of the American Academy of Political and Social Science 620(November 2008):177-93.

Menjívar, Cecilia and Leisy J. Abrego. 2012. "Legal Violence: Immigration Law and the Lives of Central American Immigrants." American Journal of Sociology 117(5):1380-421.

Menjívar, Cecilia and Sarah M. Lakhani. 2016. "Transformative Effects of Immigration Law: Migrants' Personal and Social Metamorphoses through Regularization." American Journal of Sociology 121(6):1818-55.

Meyer, Ian H. 2003. "Prejudice, Social Stress, and Mental Health in Lesbian, Gay, and Bisexual Populations." Psychological Bulletin 129(5):674-97.

Migration Policy Institute. 2017, "Deferred Action for Childhood Arrivals (Daca) Data Tools". Retrieved September 1, 2017, (https://www.migrationpolicy.org/programs/datahub/deferred-action-childhood-arrivals-daca-profiles).

Mize, Trenton D. 2019. "Best Practices for Estimating, Interpreting, and Presenting Nonlinear Interaction Effects." Sociological Science 6(4):81-117.

Nakano Glenn, Evelyn. 2011. "Constructing Citizenship: Exclusion, Subordination, and Resistance." American Sociological Review 76(1):1-24.

Nicholls, Walter J. 2013. The Dreamers: How the Undocumented Youth Movement Transformed the Immigrant Rights Debate. Palo Alto: Stanford University Press.

Patler, Caitlin. 2014. "Racialized "Illegality": The Convergence of Race and Legal Status among Black, Latino, and Asian American Undocumented Young Adults." Pp. 93-113 in Scholars and Southern Californian Immigrants in Dialogue: New Conversations in Public Sociology, edited by V. Carty, R. Luévano and T. Woldemikael. Lanham, MD: Lexington Books.

Patler, Caitlin. 2018a. "“Citizens but for Papers:” Undocumented Youth Organizations, AntiDeportation Campaigns, and the Boundaries of Belonging." Social Problems 65(1):95115. doi: 10.1093/socpro/spw045.

Patler, Caitlin. 2018b. "To Reveal or Conceal: How Diverse Undocumented Youth Navigate Legal Status Disclosure." Sociological Perspectives 61(6):857-73. doi: 10.1177/0731121418775092.

Patler, Caitlin and Whitney N. Laster Pirtle. 2018. "From Undocumented to Lawfully Present: Do Changes to Legal Status Impact Psychological Wellbeing among Latino Immigrant 
Young Adults?". Social Science \& Medicine 199(1):39-48. doi:

10.1016/j.socscimed.2017.03.009.

Patler, Caitlin, Erin Hamilton, Kelsey Meagher and Robin Savinar. 2019. "Uncertainty About Daca May Undermine Its Positive Impact on Health for Recipients and Their Children." Health Affairs 38(5):738-45.

Pearlin, Leonard I. and Alex Bierman. 2013. "Current Issues and Future Directions in Research into the Stress Process." Pp. 320-240 in Handbook of the Sociology of Mental Health, edited by C. S. Aneshensel, J. C. Phelan and A. Bierman: Springer.

Plascencia, Luis F.B. 2012. Disenchanting Citizenship: Mexican Migrants and the Boundaries of Belonging. New Brunswick, NJ: Rutgers University Press.

Pope, Nolan G. 2016. "The Effects of Dacamentation: The Impact of Deferred Action for Childhood Arrivals on Unauthorized Immigrants." Journal of Public Economics 143:98114.

Potochnick, Stephanie R. and Krista M. Perreira. 2010. "Depression and Anxiety among FirstGeneration Immigrant Latino Youth: Key Correlates and Implications for Future Research." The Journal of nervous and mental disease 198(7):470.

Prochaska, Judith J., Hai-Yen Sung, Wendy Max, Yanling Shi and Michael K. Ong. 2012. "Validity Study of the K6 Scale as a Measure of Moderate Mental Distress Based on Mental Health Treatment Need and Utilization." International Jounral of Methods in Psychiatric Research 21:88-97.

Rodríguez, Michael A., Maria-Elena Young and Steven P. Wallace. 2015. "Creating Conditions to Support Healthy People: State Policies That Affect the Health of Undocumented Immigrants and Their Families." Los Angeles, CA: University of California Global Health Institute.

Roth, Benjamin J. 2018. "The Double Bind of Daca: Exploring the Legal Violence of Liminal Status for Undocumented Youth." Ethnic and Racial Studies:1-18.

Sugie, Naomi F. 2018. "Work as Foraging: A Smartphone Study of Job Search and Employment after Prison." American Journal of Sociology 123(5):1453-91.

Teranishi, Robert T., Carola Suárez-Orozco and Marcelo Suárez-Orozco. 2015. "In the Shadows of the Ivory Tower: Undocumented Undergraduates and the Liminal State of Immigration Reform." The Institute for Immigration, Globalization, and Education: University of California, Los Angeles.

Terriquez, Veronica. 2017. "Legal Status, Civic Organizations, and Political Participation among Latino Young Adults." The Sociological Quarterly 58(2):315-36.

Thoits, Peggy A. 1991. "On Merging Identity Theory and Stress Research." Social Psychology Quarterly 54(2):101-12.

Thomeer, Mieke Beth, Allen J. LeBlanc, David M. Frost and Kayla Bosen. 2018. "Anticipatory Minority Stressors among Same-Sex Couples: A Relationship Timeline Approach." Social Psychology Quarterly 81(2):126-48.

U.S. Department of State. 2017, "Non-Immigrant Visa Statistics". Retrieved October 21, 2017, (https://travel.state.gov/content/visas/en/law-and-policy/statistics/non-immigrantvisas.html).

USCIS. 2018, "Number of I-821d, Consideration of Deferred Action for Childhood Arrivals by Fiscal Year, Quarter, Intake and Case Status: 2012-2018 (July 31, 2018)". Retrieved October 10, 2018. 
Valdivia, Carolina. 2018. "Expanding Geographies of Deportability: How Immigration Enforcement at the Local-Level Affects Undocumented and Mixed-Status Families." Law \& Policy 41(1):103-19.

Vaquera, Elizabeth, Elizabeth Aranda and Isabel Sousa-Rodriguez. 2017. "Emotional Challenges of Undocumented Young Adults: Ontological Security, Emotional Capital, and WellBeing." Social Problems 64(2):298-314.

Vega, William A. and Ruben G. Rumbaut. 1991. "Ethnic Minorities and Mental Health." Annual Review of Sociology 17:351-83.

Venkataramani, Atheendar S., Sachin J. Shah, Rourke O'Brien, Ichiro Kawachi and Alexander C. Tsai. 2017. "Health Consequences of the Us Deferred Action for Childhood Arrivals (Daca) Immigration Programme: A Quasi-Experimental Study." The Lancet 2017(2):e175-81.

Wong, Tom K., Greisa Martinez Rosas, Adam Luna, Henry Manning, Adrian Reyna, Patrick O'Shea, Tom Jawetz and Philip E. Wolgin. 2017, "Daca Recipients' Economic and Educational Gains Continue to Grow", Washington, D.C.: Center for American Progress. Retrieved May 1, 2018 (https://www.americanprogress.org/issues/immigration/news/2017/08/28/437956/dacarecipients-economic-educational-gains-continue-grow/). 


\section{NOTES}

${ }^{1}$ DACA targets undocumented youth who meet the following criteria: came to the U.S. before age 16; were at least 15 years old and younger than 31 in June 2012; have continuously resided in the U.S. since June 2007; are current students or high school/GED graduates, or honorably discharged veterans; and have no criminal record.

2 This uncertainty is illustrated by the Trump administration's stance on DACA, both on the campaign trail and following the election and subsequent rescinding. Journalists have described this period of "political and legal limbo" as " a kind of purgatory [for recipients] that few of us can imagine." See https://www.washingtonpost.com/education/2018/11/09/congress-must-endpurgatory-dreamers/?utm_term $=.5$ edf4fbeb68f (Retrieved November 9, 2018).

${ }^{3}$ In November 2014, President Obama announced an expanded version of DACA that targeted a much larger swath of undocumented youth (referred to as Extended DACA) and a complementary program for the undocumented parents of U.S. citizens and LPRs, the Deferred Action for Parents of Americans and Lawful Permanent Residents (DAPA). These programs were immediately challenged in the courts and fiercely litigated all the way up to the Supreme Court. In June 2016, the Supreme Court reached a split decision in the case, therefore upholding the lower court's injunction and blocking the program.

${ }^{4}$ In his June 16, 2015 presidential bid announcement, then-candidate Trump stated that immigrants from Mexico are "people that have lots of problems, and they're bringing those problems with us. They're bringing drugs. They're bringing crime. They're rapists. And some, I assume, are good people." In that speech he also said, "I will build a great, great wall on our 
southern border. And I will have Mexico pay for that wall. Mark my words.” In August 2015, Trump stated that he would end birthright citizenship if elected president. See:

http://time.com/3923128/donald-trump-announcement-speech/ and

https:/www.npr.org/sections/itsallpolitics/2015/08/22/433621593/will-gops-efforts-to-reach-outto-hispanics-survive-these-primaries (retrieved November 9, 2018).

${ }^{5}$ See: https://www.washingtonpost.com/news/the-fix/wp/2015/08/17/donald-trump-says-illegalimmigrants-have-to-go-only-31-percent-of-republicans-agree/?utm term $=.6855 \mathrm{f0fd} 649 \mathrm{~b}$ (retrieved November 9, 2018).

${ }^{6}$ See: https://www.nytimes.com/2020/06/18/us/trump-daca-supreme-court.html (retrieved July 26, 2020).

${ }^{7}$ Nonresponse rates in the CHIS are generally low $(<1 \%)$. Nevertheless, to improve usability of the data, the CHIS replaces missing values for most variables in the survey (see https://healthpolicy.ucla.edu/chis/design/Pages/methodology.aspx). In this analysis there are no missing data for age, male, and household poverty level. Our dependent variable, the Kessler 6 score, is missing for $0.05 \%$ of the Latina/o analytic sample.

${ }^{8}$ Latina/o was defined as anyone born in Mexico, Central America or Other Latin America.

${ }^{9}$ All groups meet the following DACA eligibility criteria: they were ages $15-30$ in 2012 ; and they have either a high school degree, a GED, are currently enrolled in school, or have served in the military. Documented migrants and the DACA-eligible group — our treatment group — satisfy the additional criteria of having arrived in the U.S. in 2007 or earlier and being age 15 or Patler, Hamilton \& Savinar - 45 
younger at the time of arrival. We restrict all groups to the DACA age criteria so they age similarly over time and program impacts are not confounded by age. Two additional DACA criteria are not directly observable in the CHIS data: criminal record and continuous residence in the United States from 2007 to 2012 . We assume that respondents have resided continuously in the United States since the year they arrived.

${ }^{10}$ The CHIS asks: "Are you a citizen of the United States?" and "Are you a permanent resident with a green card? Your answers are confidential and will not be reported to immigration services." For both questions, answer choices include "yes," "no," and "application pending". We code respondents with applications pending for citizenship as LPRs. We coded as undocumented respondents who answer "no" to both questions or "no" to citizenship and “application pending" to LPR status.

11 The K6 question reads as follows:

"The next questions are about how you have been feeling during the past 30 days:

1. About how often during the past 30 days did you feel nervous-Would you say all of the time, most of the time, some of the time, a little of the time, or none of the time?

2. During the past 30 days, about how often did you feel hopeless-all of the time, most of the time, some of the time, a little of the time, or none of the time?

3. During the past 30 days, about how often did you feel restless or fidgety?

4. How often did you feel so depressed that nothing could cheer you up?

5. During the past 30 days, about how often did you feel that everything was an effort?

6. During the past 30 days, about how often did you feel worthless?" 
Responses to each of the six questions are scored as follows: all (four points), most (three points), some (two points), a little (one point), and none (zero points).

12 Workshops were held at libraries, public schools, and the Los Angeles Convention Center and co-hosted by the Los Angeles Unified School District, the Los Angeles Mayor's Office, and immigrants' rights and legal service organizations. The workshops were advertised widely in English- and Spanish-language media. A total of 1,102 participants were over 18, provided contact information, and spoke English; our response rate was therefore 67 percent. The Wave 2 response rate was 61 percent.

13 The survey contains items from several standard survey tools including: the American Community Survey, California Health Interview Survey, California Young Adult Study, and National Political Survey. Many other questions were original questions designed to test the impact of DACA on various outcomes. All questions were piloted with focus groups of DACAeligible and undocumented young adults. The mean survey length was 32 minutes for Wave 1 and 25 minutes for Wave 2 and all respondents received a gift card and know-your-rights information to thank them for participating.

${ }^{14}$ All interviews took place in person or on the phone, and lasted between 45 minutes and two hours. Respondents received a gift card to thank them. 
15 This is slightly higher than the 22 percent of Latino young adults in California (age 18-26) who were a member of a civic organization in the 2012 California Young Adult Study (Terriquez 2017).

${ }^{16}$ See: https://www.nytimes.com/2020/06/19/us/politics/trump-daca.html (retrieved July 26, 2020). 